Körber, M., Baseler, E., \& Bengler, K. (2018). Introduction matters: Manipulating trust in automation and reliance in automated driving. Applied Ergonomics, 66, 18-31. https://doi.org/10.1016/j.apergo.2017.07.006

\title{
Introduction Matters: Manipulating Trust in Automation and Reliance in Automated Driving
}

\author{
Moritz Körber \\ Chair of Ergonomics, \\ Technical University of \\ Munich \\ Boltzmannstraße 15, 85747 \\ Garching \\ Tel: +49 8928915376 \\ moritz.koerber@tum.de
}

\author{
Eva Baseler \\ Chair of Ergonomics, \\ Technical University of \\ Munich \\ Boltzmannstraße 15, 85747 \\ Garching \\ Tel: +49 8928915376 \\ eva.baseler@tum.de
}

\author{
Klaus Bengler \\ Chair of Ergonomics, \\ Technical University of \\ Munich \\ Boltzmannstraße 15, 85747 \\ Garching \\ Tel: +49 8928915400 \\ bengler@tum.de
}

Correspondence concerning this article should be addressed to Moritz Körber, Chair of Ergonomics, Technical University of Munich, Boltzmannstraße 15, D - 85747 Garching, Tel: +49 89289 15376, Email: moritz.koerber@tum.de

\begin{abstract}
Trust in automation is a key determinant for the adoption of automated systems and their appropriate use. Therefore, it constitutes an essential research area for the introduction of automated vehicles to road traffic. In this study, we investigated the influence of trust promoting (Trust promoted group) and trust lowering (Trust lowered group) introductory information on reported trust, reliance behavior and takeover performance. Forty participants encountered three situations in a 17-minute highway drive in a conditionally automated vehicle (SAE Level 3). Situation 1 and Situation 3 were non-critical situations where a take-over was optional. Situation 2 represented a critical situation where a take-over was necessary to avoid a collision. A non-driving-related task (NDRT) was presented between the situations to record the allocation of visual attention. Participants reporting a higher trust level spent less time looking at the road or instrument cluster and more time looking at the NDRT. The manipulation of introductory information resulted in medium differences in reported trust and influenced participants' reliance behavior. Participants of the Trust promoted group looked less at the road or instrument cluster and more at the NDRT. The odds of participants of the Trust promoted group to overrule the automated driving system in the non-critical situations were 3.65 times (Situation 1) to 5 times (Situation 3) higher. In Situation 2, the Trust promoted group's mean take-over time was extended by $1154 \mathrm{~ms}$ and the mean minimum time-to-collision was 933 ms shorter. Six participants from the Trust promoted group compared to no participant of the Trust lowered group collided with the obstacle. The results demonstrate that the individual trust level influences how much drivers monitor the environment while performing an NDRT. Introductory information influences this trust level, reliance on an automated driving system, and if a critical take-over situation can be successfully solved.
\end{abstract}

Keywords: automated driving, trust in automation, reliance.

This research has solely been funded by the Chair of Ergonomics, Technical University of Munich.

Declaration of Conflicting Interests: The authors declare that they had no conflicts of interest with respect to his authorship or the publication of this article. 


\title{
Introduction Matters: Manipulating Trust in Automation and Re- liance in Automated Driving
}

\author{
Moritz Körber, Eva Baseler, \& Klaus Bengler
}

\section{Introduction}

The introduction of automated vehicles to road traffic is motivated by several predicted, beneficial outcomes (Maurer, Gerdes, Lenz, \& Winner, 2015; Stanton \& Young, 1998) such as mitigating the negative effects of routine drives on drivers' health and compensating the negative effects of the predicted increase in passenger traffic by increasing traffic efficiency (Payre, Cestac, \& Delhomme, 2014; Roberts, Hodgson, \& Dolan, 2011). Beyond that, although advancements in passive and active safety technologies have led to a significant reduction in road accidents (Choi \& Ji, 2015), European data, for example, show that 26,000 road fatalities were still reported in the European Union in 2015 (European Commission, 2016). It is assumed that fully automating the driver's tasks will reduce human error, such as speeding or distraction, and, thereby, the number of fatalities further still. However, these claimed benefits may only occur if automated vehicles are successfully implemented into road traffic and trust in this technology is a vital precondition for this. Ghazizadeh, Lee, and Boyle (2012) stated in their Automation Acceptance Model that trust is a crucial contributor to an individual's acceptability of automation technology and several previous studies have empirically shown that trust is a key determinant for reliance on automated systems (Bailey \& Scerbo, 2007; Muir \& Moray, 1996), adoption of automation (Gefen, Karahanna, \& Straub, 2003; Lee \& Moray, 1994), and the intention to use autonomous vehicles (Choi \& Ji, 2015). In other words, “operators tend to use automation that they trust while rejecting automation that they do not” (Pop, Shrewsbury, \& Durso, 2015). Multiple research disciplines focus on trust, and there are several models with multiple dimensions of trust that more or less overlap. Based on Mayer, Davis, and Schoorman (1995) and Lee and See (2004), we define trust in automation as "the attitude of a user to be willing to be vulnerable to the actions of an automation based on the expectation that it will perform a particular action important to the user, irrespective of the ability to monitor or to intervene." This definition implies that trust is a multidimensional construct that is based on relevant characteristics of the automated system (e.g., reliability, predictability) and the trustor himself (e.g., propensity to trust). Driving automation represents a novel and complex technology and, contrary to flight automation in aviation, its users will not be experts who have a deep understanding of its functionality and principles (Körber \& Bengler, 2014). Thus, its use represents a situation of uncertainty and vulnerability in which the user entrusts his well-being to the automated driving system (Lee \& See, 2004; Walker, Stanton, \& Salmon, 2016). However, trusting a system is not a binary all-or-none decision. The conceptualization of trust in a system rather refers to trusting and reliance as a graded process, with the degree of trust being dynamic and situational (Hoff \& Bashir, 2015; Lee \& See, 2004). This degree does not have to exclusively concern a system as a whole but may be specific to particular functions of it. For example, in a study on a supervisory process control task, trust was distinct to the specific automatic controller (Lee \& Moray, 1994) and an automation failure did not cause trust to decline in the remaining similar, but independent automatic controllers (Lee \& Moray, 1992; Muir \& Moray, 1996). In contrast, Keller and Rice (2009) found that when a completely reliable aid was presented with an unreliable aid, operators tended to rate both aids the same in a global, system-wide trust rating rather than treating them as different systems with different reliabilities (component-specific trust). The exact degree of functional specificity is probably moderated by an operator's experience with the system, its complexity, the information presented to the operator and their goals in operating the system (Lee \& See, 2004). Indeed, this reflects the conceptualization of trust as a mainly affective response with influences 
by analytic and analogical processes. Since the future driving automation users will not be a homogenous group of trained experts, potential variability in driver characteristics such as trust can lead to very different outcomes, especially in time-critical situations like take-over situations (Creaser \& Fitch, 2015; Körber, Gold, Lechner, \& Bengler, 2016). For example, in June 2016, the first fatal accident caused by a self-driving car occurred. The driver completely relied on the Autopilot function of his Tesla Model $\mathrm{S}$, which misinterpreted a white tractor-trailer crossing the highway against a bright sky for a road sign overhead (The Guardian, 2016). Accordingly, one of the two published Research Needs Statements regarding human factors research on automated vehicles by the Transportation Research Board (TRB) pertains to the misuse and abuse of automated vehicles (Creaser \& Fitch, 2015). Thus, to ensure a safe introduction of automated vehicles to road traffic, it is crucial to take trust into account. Otherwise, the benefits of driving automation could vanish even if the system is used.

\subsection{The role of trust in automated driving}

Contrary to autonomous vehicles, conditionally automated driving still requires a driver. In SAE Level 3 (SAE International, 2016), drivers are included in the control loop as a fallback level and will be required to take over manual control at system limits. Beyond that, it is also possible that the system might require a transfer to Level 2 if the conditions necessitate it (Creaser \& Fitch, 2015). An automated driving system will allow the driver to take his eyes off the road and engage in NDRTs and driving simulator studies show that drivers are willing to do so, possibly increasing the demand of a take-over situation (Carsten, Lai, Barnard, Jamson, \& Merat, 2012; Llaneras, Salinger, \& Green, 2013; Radlmayr, Gold, Lorenz, Farid, \& Bengler, 2014). This act of reliance is only performed if the driver trusts driving automation enough to completely hand over the driving task. However, trust predicts not only whether an automated system is used but also how it is used: Parasuraman and Riley (1997) categorized the interaction with automation into four styles which can be linked to operator's trust in automation. Among Use, Disuse, Abuse, the authors highlight the negative effects of Misuse, inappropriate overtrust when the operator's trust exceeds the automated system's capabilities. Mahr and Müller (2011) stated in their model that too much trust leads to over-reliance on automation and therefore to a risk adaption, i.e. the driver takes risks he would not have taken without an automated system. Operators then tend to be vulnerable to monitoring failures (Bagheri \& Jamieson, 2004; Bailey \& Scerbo, 2007) and tend to exhibit longer reaction times (Beller, Heesen, \& Vollrath, 2013; Helldin, Falkman, Riveiro, \& Davidsson, 2013) or poorer reaction quality in critical events (McGuirl \& Sarter, 2006; de Waard, van der Hulst, Hoedemaeker, \& Brookhuis, 1999). Hence, not only a minimum level but an appropriate level of trust is crucial: The operator has to know the capabilities of an automated system and should monitor it adequately when it is close to the limits of its capability (Carlson, Drury, Desai, Kwak, \& Yanco, 2014). Otherwise, the consequences are unexpected situations in which the driver may not able to react in time.

The take-over of vehicle control can be critical if the automated driving system is operated in an unfamiliar, unexpected or unstructured environment, situation or condition, because then the situation's demand may exceed the capacity for reacting since such situations have an increased demand (Shinar, Tractinsky, \& Compton, 2005; Wagner \& Koopman, 2015). For example, Payre, Cestac, and Delhomme (2016) found a higher take-over time with increasing trust in an emergency situation if training was insufficient. Consistent across different levels of automation, inappropriate levels of trust lead to extended reaction times or poorer reaction quality in hazardous situations (Abe, Itoh, \& Tanaka, 2002; McGuirl \& Sarter, 2006; Parasuraman \& Riley, 1997). The causal mechanism could lie in participants’ monitoring strategy: Muir and Moray (1996) as well as Bagheri and Jamieson (2004) found a decrease in monitoring with increasing trust. Hergeth et al. (2016) also reported a negative correlation between participant's trust in automation and the extent of monitoring of a highly automated driving system during the engagement with an NDRT. Accordingly, better-calibrated trust, achieved by the display of 
system confidence or reliability (Dzindolet, Peterson, Pomranky, Pierce, \& Beck, 2003; McGuirl \& Sarter, 2006), led to faster braking responses in a study by Seppelt and Lee (2007). Beller et al. (2013) showed that the presentation of information on an automated system's uncertainty improves situation awareness, improves a driver's mental model of the automated driving system, increases trust, and leads to an increased time to collision in the event of an automation failure. Drivers in the study of Helldin et al. (2013), who were informed of the automated system's uncertainty, were better prepared in take-over situations while, on average, spending more time doing other activities. This study aims to investigate the relationship between trust, reliance behavior and take-over performance in conditional automated driving in greater detail. Firstly, we investigate if trust and reliance behavior can be manipulated by prior information (see next section). Secondly, trust is one factor, besides others such as self-confidence, that influences reliance (Lee \& Moray, 1992; Lee \& See, 2004), but it does not completely determine it because intentions and attitudes do not completely determine behavior (Ajzen \& Fishbein, 1980; Meyer, 2004). Therefore, we use explicit behavioral measures in the form of reliance behavior as well as implicit measures in the form of eye tracking. Furthermore, the study aims to investigate the relationship between reported trust and the safety-critical outcome take-over performance. The following relationships are expected:

H1: Trust is negatively correlated with monitoring of the automated driving system.

H2: Trust is positively correlated with reliance on the automated driving system.

H3: Trust is positively correlated with take-over time and negatively correlated with take-over quality.

\subsection{Prior information influences trust}

In contrast to the domain of aviation, the operators of automated vehicles will not be professional experts but laypersons (Casner, Hutchins, \& Norman, 2016). Automated driving and the engagement in NDRTs represents a novel situation for a driver, in which trust is particularly important because it determines reliance in complex and unanticipated situations that are not completely understood (Lee \& See, 2004; Meyer, 2001). In such situations, instructions and training with automation form an operator's expectations, prior knowledge and understanding (Hoff \& Bashir, 2015). How an automation is presented to an operator constitutes his expectations of the automated system's reliability (Barg-Walkow \& Rogers, 2016; Mayer, Rogers, \& Fisk, 2009) and the expectations, in turn, constitute the perception of an automation's reliability (Madhavan \& Wiegmann, 2005; Pop et al., 2015). Accordingly, Beggiato and Krems (2013) found a negative relationship between the number of potentially critical situations that are presented in preliminary information, and initial trust in and acceptance of an ACC system. Explicit statements on system reliability in the introduction determine initial reliance, compliance and tendency to over-reliance (Madhavan \& Wiegmann, 2005; Mayer, Sanchez, Fisk, \& Rogers, 2006). Initial trust is higher before the automated system is used if no limitations of a fully automated system are mentioned (Biassoni, Ruscio, \& Ciceri, 2016). Skitka, Mosier, Burdick, and Rosenblatt (2000) also found that training in which automation bias and its negative effects was emphasized led to a smaller number of commission errors but had no effect on omission errors. This effect is greater when participants actually experienced automation failures during training than for only being instructed that the automated system may fail (Bahner, Hüper, \& Manzey, 2008). Sauer, Chavaillaz, and Wastell (2015) found that the level of system reliability experienced during training influenced the trust in an automated system and the degree of automation bias in the following test session. In this study, we aim to transfer the mentioned findings to conditional automated driving and investigate if prior information determines the interaction with an automated driving system. Given the mentioned findings, automation that raises positive expectations of its performance (Schaefer, Chen, Szalma, \& Hancock, 2016), signals high reliability (Mayer 
et al., 2006) and is experienced as reliable (Sauer et al., 2015) should increase subjective trust in automation. Based on this, we expect the following relationship:

H4: The degree of competence and reliability of an automated system that is described in an introduction and is experienced in an introductory drive is positively correlated to the subjective trust in automation.

\section{Method}

\subsection{Experimental design}

The experiment was designed as a between-subjects design with two groups, (1) Trust Lowered and (2) Trust Promoted. The Trust Promoted group received trust-promoting information that should increase trust in automation, while the Trust Lowered group received trust-lowering information that should decrease trust. Participants in both groups then experienced the same three situations in the same order. The experimental procedure is depicted in Figure 1. As already mentioned, trusting is not an all-or-none decision. Rather than completely establishing or eliminating trust, we expect the prior information to raise or lower trust. Furthermore, the initial trust level as well as the change in trust level by the prior information is dependent on stable individual differences in the general propensity to trust automated systems (Lee \& See, 2004). Hence, we still expect variance of the trust scores within the experimental groups and, therefore, investigate trust on individual level and group level.

\subsection{Sample}

A total of $n=40$ participants took part in this study, 12 (60\%) female and 8 (40\%) male in the Trust Lowered group and 10 female (50 \%) and 10 male (50 \%) in the Trust Promoted group. The mean age of the Trust Lowered group was $M=26.65(S D=4.49)$ with a range from 19 to 37 years, the mean age for the Trust Promoted group was $M=25.85(S D=1.85$ ) with a range from 22 to 29 years. Participants were required to have held a driver's license for at least one year. Participants in the Trust Lowered group had held their drivers' licenses for a mean of $M=9.15(S D=4.12)$ years, while participants in the Trust Promoted group had held their drivers' licenses for a mean of $M=7.93(S D=1.65)$ years. Annual mileage by trust group is listed in Table 1. Since a positive view of technology influences the perception of automation and promotes complacency (Lee \& See, 2004), we ensured equivalence of the groups in the covariate affinity for technology, measured by a questionnaire developed by Feuerberg, Bahner, and Manzey (2005), in this study. If participants reported any impairments to their sight, the use of adequate correction was ensured. Table 2 and Table 3 list the prior experience of the participants with a driving simulator and with automated driving. Participation was rewarded with candies.

\begin{tabular}{lcccc}
\hline & $<5,000$ & $\begin{array}{c}5,000- \\
10,000\end{array}$ & $\begin{array}{c}10,000- \\
20,000\end{array}$ & $>20,000$ \\
\hline Lowered & 9 & 6 & 4 & 1 \\
Promoted & 6 & 11 & 3 & 0 \\
\hline Total & 15 & 17 & 7 & 1 \\
\hline
\end{tabular}

Table 1: Annual mileage in kilometers by group.

\begin{tabular}{lcccccc}
\hline & \multicolumn{3}{c}{ ACC } & \multicolumn{2}{c}{ LKA } & \multicolumn{2}{c}{ LDW } \\
& Yes & No & Yes & No & Yes & No \\
\hline Lowered & 3 & 14 & 0 & 20 & 0 & 20 \\
Promoted & 0 & 18 & 1 & 18 & 1 & 18 \\
\hline Total & 3 & 32 & 1 & 38 & 1 & 38 \\
\hline Table 2: Experience with driver assistance systems \\
by group; ACC = adaptive cruise control; LKA = \\
lane keeping assistance; LDW = lane departure \\
warning; missing = no response or does not know.
\end{tabular}




\begin{tabular}{lcccc}
\hline & \multicolumn{2}{c}{ Simulator study } & \multicolumn{2}{c}{ Automated driving study } \\
& Participated & Not yet participated & Participated & Not yet participated \\
\hline Lowered & 8 & 12 & 3 & 17 \\
Promoted & 7 & 13 & 6 & 14 \\
\hline Total & 15 & 25 & 9 & 31 \\
\hline
\end{tabular}

Table 3: Prior participation in experiments by groups.

\subsection{Dependent variables}

\subsubsection{Reliance behavior}

Trust is defined as the willingness to be vulnerable to another party and, therefore, a suitable measurement is a situation that assesses the extent to which a trustor is willing to voluntarily become vulnerable by relying on the automated system (Schoorman, Mayer, \& Davis, 2007). We implemented two situations (Situation 1, Situation 3) that are solved by the automated driving system but could have evolved into an accident. Thus, a take-over was not obligatory or requested but is a reasonable action if one does not trust the automated driving system. To evaluate take-over performance a critical situation with an obligatory take-over, Situation 2, was implemented as well. We implemented interim experimental stages (Interim 1-3) before each situation in which the participants should engage in the NDRT. The interims were implemented to record the allocation of attention between NDRT and monitoring of the traffic situation by eye tracking.

Situation 1 represents a slower-moving $(80 \mathrm{~km} / \mathrm{h})$ truck that functions as an obstacle on the participant's lane. The automated vehicle approaches the truck up to a headway distance of 35 meters. It then overtakes the truck with a speed of $100 \mathrm{~km} / \mathrm{h}$. Thus, the ego vehicle comes close to the truck but still overtakes without a collision. The close overtaking maneuver represents a vulnerable situation since it is not clear for a long time whether the automated driving system overtakes the vehicle correctly. Therefore, we assume that a person who does not trust the automated driving system will intervene and overtake the truck by himself. Lower trust should also lead to an earlier intervention, i.e. we expect a negative correlation between trust and time until optional take-over. To ensure that every participant was aware of this situation, the NDRT was shut off seven seconds before the situation began.

Situation 2 represents a critical situation with an obligatory take-over. A broken-down vehicle, with a breakdown triangle directly in front on the same lane was used as an obstacle. The situation was introduced with a headway vehicle driving at the same speed as the ego vehicle that obstructed the view on the obstacle. With time-to-collision (TTC) of 8 seconds, the headway vehicle changed lanes, allowing the participant a view of the obstacle at 7 seconds TTC. Thus, a participant who monitors the road frequently can react to the situation before the take-over request (TOR) was emitted. At $4 \mathrm{~s}$ TTC (111.11 meters), an auditory TOR in the form of a doubled beep $(2,800 \mathrm{~Hz}, 74 \mathrm{~dB})$ was emitted, requesting the driver to take-over vehicle control. At the same particular point in time, the automated driving system was turned off, resulting in a drag torque of $0.64 \mathrm{~m} / \mathrm{s}^{2}$.

Situation 3 was similar to Situation 1 in the sense that it represented a close, but ultimately uncritical situation with no obligatory take-over. Again, a slower-moving truck $(80 \mathrm{~km} / \mathrm{h})$ was the headway vehicle. At 345 meters distance, the longitudinal control was shut off momentarily and, therefore, the gap between the vehicles was reduced up to a distance of 35 meters, at which point the ACC has been activated again. This avoided a collision and a take-over was not necessary. However, the reactivation of the ACC was set at a quite close headway distance, therefore, participants who do not trust the automated driving system are expected to brake before the ACC was reactivated in order to avoid a collision. Again, to ensure that every participant was aware of this situation, the NDRT was shut off seven seconds before the situation began. 


\subsubsection{Take-over time and quality}

Dependent variables for the take-over situation were take-over time, minimum time-to-collision, maximum lateral acceleration and maximum longitudinal acceleration. According to (Gold \& Bengler, 2014), take-over time (TOT) was defined as the time between the TOR and the first conscious reaction by the driver, i.e. a change of $10 \%$ of the maximum brake pedal position or more than two degrees in steering wheel angle. Take-over quality comprises the evasive maneuver as well as the stabilization on the new lane and was measured by the minimum time-to-collision (minTTC), which is defined as the current remaining time until a collision with an object is imminent, assuming constant speed and direction. Further measures for take-over quality are maximum longitudinal acceleration and the maximum lateral acceleration of the ego vehicle that occurred between the TOR and 166 meters after the obstacle. The last indicator for take-over quality was the involvement in a collision.

\subsection{Material and apparatus}

\subsubsection{Information material}

At the beginning of the experiment, an introductory video on automated driving published by the ÖAMTC (Österreichische Automobil-, Motorrad- und Touringclub, 2014), was presented on an Apple MacBook Pro notebook with a 13 " display. In this video, the basic functionality of automated driving, sensors, and trajectory planning was explained within a conditionally automated drive on an Austrian highway. The Trust Promoted group watched the same video as the Trust Lowered group, however, the final, non-critical take-over caused by the upcoming exit from the highway was cut from the video of the Trust Promoted group. Both groups, therefore, watched a video of a perfectly-functioning automated driving system, but the Trust Lowered group also saw a non-critical take-over situation in addition, whereas the Trust Promoted group did not see this explicit reminder of the automated driving system's limitations. As second part of the introductory information, the two groups were introduced to the functionality of the automated driving system in text form. Both groups received the same text, except that in the Trust Lowered group, a take-over situation was described as possible at any time whereas in the Trust Promoted group it was described as unlikely to happen, but possible. Also, the Trust Lowered group was explicitly reminded that they are ultimately responsible for their vehicle and road safety at all times; this part was left out for the Trust Promoted group at this point. The third part of the introductory information material was represented by the introductory drive. This drive lasted for about two minutes and was set on a similar highway track to the experimental drive. For the first part of this drive, the participants were instructed to drive manually in order to get comfortable with driving in a driving simulator. Next, they were instructed to switch on the automated driving system and were told that they could overrule the automated driving system with their manual input at any time. After about one minute of driving, the participants were instructed to change to the right lane with driving automation activated. Both groups, Low and High, then experienced a take-over situation, however, the criticality was varied based on the experimental condition. The Trust Promoted group received the TOR with no surrounding traffic and no obstacle and thereby had to regain manual control in a completely non-critical situation. The Trust Lowered group also received the TOR but at six seconds TTC to a broken-down vehicle as an obstacle. Therefore, they had to regain manual control and change lanes to avoid a collision. There was no surrounding traffic, the participants were not distracted, and no other complicating conditions were present, thus, it was a more critical take-over situation than the Trust Promoted group, but still very easy to solve. 


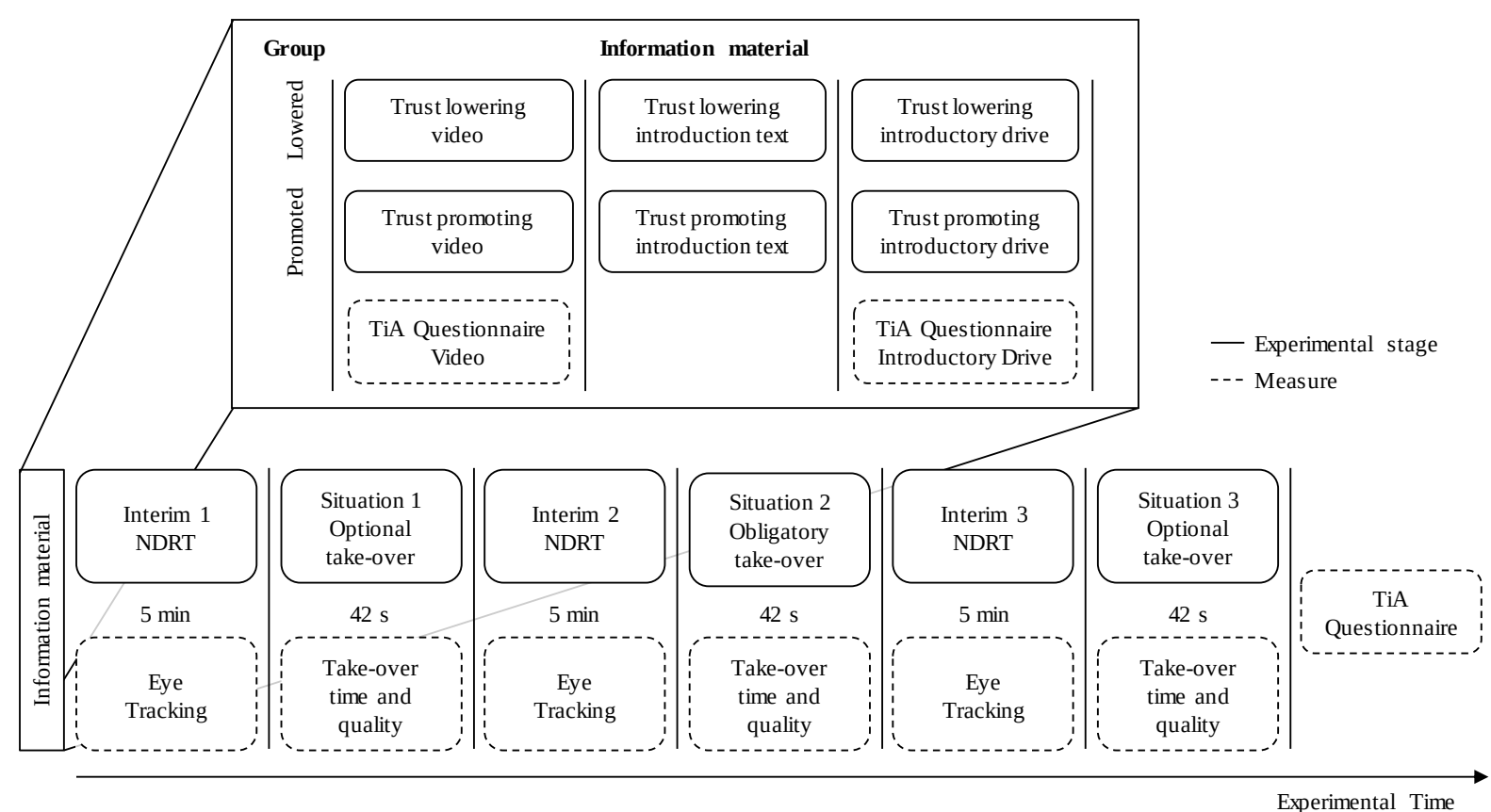

Figure 1: Procedure and measures of the experiment.

\subsubsection{Trust in Automation questionnaire}

We used the German version of the questionnaire Trust in Automation (TiA) developed by Körber (2015), which contains 19 items on a Likert-type rating scale from 1 (= strongly disagree) to 5 (= strongly agree). Internal consistency, as well as construct validity, have been shown in this publication. The questionnaire is structured into five subscales (Reliability/Competence, Familiarity, Trust, Understanding, Intention of Developers) which each contain between two and four items. Sample items are "I trust the system" (Item 9) or "The system might make sporadic errors" (Item 15). The trust-influencing information was focused on manipulating trust by different information regarding the automated driving system's competence. Thus, for this experiment, we analyzed the complete questionnaire but also focused on the subscales Trust and Competence which have been analyzed as a single subscale as well.

\subsubsection{Affinity for technology questionnaire}

The subscale Affinity for Technology within the questionnaire Potential for Complacency (Feuerberg et al., 2005) contains eleven items formulated as statements with a Likert-type answer mode from 1 (= not true at all) to 5 (= completely true). For example, Item 9 says "I am fascinated by most of the technological achievements”.

\subsubsection{Driving simulator and experimental track}

The experiment was conducted in a static driving simulator with a BMW 6 series mockup. A front field view of approximately $180^{\circ}$, as well as three additional screens for rear mirrors, were used to show the driving simulation SILAB by WIVW GmbH. Participants drove in an automated vehicle (conditional driving automation; Level 3 in SAE International, 2016) at a speed of $100 \mathrm{~km} / \mathrm{h}$ on a six-lane highway (three lanes in each direction). The implemented automated driving system was able to carry out longitudinal as well as lateral control and to overtake slower vehicles. Medium traffic density was implemented. The whole experimental drive lasted 17 minutes. 


\subsubsection{Eye tracking system and parameters}

DIKABLIS 2.0, developed by Ergoneers GmbH, in combination with D-Lab for analysis, was used to track participants' eye movement. The system is a head-mounted camera system containing two cameras, one for field view and one to track eye movement. Eye-tracking data was analyzed according to ISO 15007-1:2014 (2014). The defined AOIs were NDRT and Monitoring (road and instrument cluster). Measures were Percentage of Time on Area of Interest (ratio representing the percentage of time that glances are within an AOI), Glance Frequency (number of glances per unit of time on an AOI), and Mean Glance Duration (mean duration of all glances toward an AOI).

\subsubsection{Non-driving-related task surrogate reference task}

Many NDRTs in an automated driving scenario, such as texting with a cell phone, using a navigation system, or a media system menu require visual-manual input (Horberry, Anderson, Regan, Triggs, \& Brown, 2006). To simulate such an NDRT, the authors chose Surrogate Reference Task (SuRT), a visual-manual task standardized in ISO 14198 (2012) in the difficulty level hard. In this task, participants have to find a single, larger circle (diameter $47 \mathrm{px}$ ) in a scatter of 50 white distractor circles (diameter $40 \mathrm{px}$ ) on a black background which is separated into six columns. To solve a trial, participants have to select the column that contains the larger circle. The task was shown at a resolution of $1366 \times 768$ pixels on a Lenovo ThinkVision LT1421 display (14 " screen size) that was placed on top of the mockup's central information display. Participants responded using a special keyboard that only contained four cursor keys. The task could be interrupted at any time. The placement of the display required the participants to re-allocate their visual focus completely away from the road/environment if they wanted to engage in the task. No feedback on task performance was given and individual task performance was not analyzed.

\subsection{Procedure}

Once they had been welcomed, participants signed their agreement to the experimental procedure, filled out a demographic questionnaire, the questionnaire Affinity for Technology, and received the introduction to the experiment (version depending on the condition) and to the automated driving system. Next, they watched the introductory video to automated driving and subsequently filled out the TiA questionnaire for the first time. After that, the participants took a seat in the vehicle and calibrated the interior to their own comfort. The eye tracking glasses were put on and were calibrated. The participants received instruction in the handling of the driving simulator and the automated driving system and were invited to try out the NDRT. If the participants indicated that they felt comfortable in the vehicle and in solving the NDRT, the introductory drive started. Next, the participants filled out the questionnaire TiA again. Afterward, the experimental drive was started. Once they had completed the drive, participants filled out the TiA for the last time and were rewarded with sweets and drinks. The total experiment time was 45 minutes.

\section{Results}

\subsection{Data analysis}

For data analysis, we relied on Bayesian parameter estimation and Bayesian hypothesis tests by Bayes Factors (BF; (Körber, Radlmayr, \& Bengler, 2016; Rouder, Speckman, Sun, Morey, \& Iverson, 2009; Schönbrodt \& Wagenmakers, 2017). A BF represents the ratio of the probability of the data given a null model to the probability of the data given an alternative model and thereby offers a gradual quantification of evidence (Schönbrodt, Wagenmakers, Zehetleitner, \& Perugini, 2015). A BF 10 of 3, for example, states that the data is 3 times more likely in the alternative model than in the null model. Lee and 
Wagenmakers (2013) provide a guideline for interpretation: $\mathrm{BF}_{10} 1-3$ anecdotal evidence, 3-10 moderate evidence, $\mathrm{BF}_{10}>10$ strong evidence. A significant $(p=0.05)$ independent samples $t$ test with $\mathrm{t}(40)$ $=2.021$ corresponds to a $\mathrm{BF}_{10}=1.49$.

We carried out the data analysis with Matlab (for driving data), JASP (Love et al., 2015), the BayesFactor package (Morey \& Rouder, 2015), and scripts by Kruschke (2015), implemented in the statistical computer software R (R Core Team, 2016) and JAGS (Plummer, 2003). If not indicated otherwise, we estimated the descriptive parameters with a normal prior and uninformative priors for its parameters $\left(\mu \sim \mathrm{N}\left(\bar{x}, 1 /\left(100 \cdot \sigma^{2}\right)\right.\right.$; $\left.\sigma \sim \mathrm{U}(\sigma / 1000, \sigma \cdot 100)\right)$. Prior distribution for the Bayesian $t$ test was a Cauchy distribution with $r=1 / \sqrt{2}$, while a uniform Beta distribution with width of $\mathrm{k}=1$ was the prior distribution for BFs on correlations (Ly, Verhagen, \& Wagenmakers, 2016). Because all of our hypotheses predict a direction of the expected effect, we used directional prior distributions to calculate the $\mathrm{BFs}$ (Dienes, 2011). $\mathrm{BF}_{+}$denotes a positive correlation, $\mathrm{BF}_{-}$a negative correlation; $\mathrm{BF}_{+0}$ indicates higher expected values in the Trust Lowered group, vice versa for $\mathrm{BF}_{-0}$. Because of the high positive skewness of the eye tracking data, the values were transformed by taking the square root and winsorized with a cutoff value at the $10^{\text {th }}$ and $90^{\text {th }}$ percentile (Wilcox, 2012).

\subsection{Questionnaires}

The questionnaire Affinity for Technology exhibited a very high internal consistency (Cronbach's alpha) of $\alpha=.88$. The mean affinity for technology for the Trust Lowered group was $M=3.48$ [3.12, 3.87] ( $S D=0.78$ ) with a range from 1.82 to 4.45 , the mean age for the Trust Promoted group was $M=3.45$ $[3.14,3.76](S D=0.64)$ with a range from 2.55 to 4.73 . The HDIs overlapped by $82.75 \%$, therefore, equivalence was assumed.

In the following, we report the descriptive sample values of the TiA questionnaires (Tables 4 to 6 and Figures 2 to 4). In the tables, $\alpha$ denotes Cronbach's alpha (internal consistency of the scale), $M$ denotes the mean score, $S D$ its standard deviation; $d$ denotes the effect size Cohen's $d$ (Grissom \& Kim, 2012); HDI denotes the highest density interval with its lower limit LL and its upper limit UL; BF denotes the Bayes Factor.

\begin{tabular}{lcccccccc}
\hline & Group & $N$ & $M$ & SD & LL & UL & $d$ & \multirow{2}{*}{ BF $_{-0}$} \\
\hline \multirow{2}{*}{ TiA Video } & Lowered & 20 & 3.17 & 0.54 & 2.90 & 3.43 & \multirow{2}{*}{0.02} & \multirow{2}{*}{0.33} \\
& Promoted & 20 & 3.19 & 0.35 & 3.02 & 3.35 & & \\
\multirow{2}{*}{ TiA Introductory Drive } & Lowered & 20 & 3.20 & 0.52 & 2.96 & 3.45 & \multirow{2}{*}{0.29} & 0.89 \\
& Promoted & 20 & 3.37 & 0.43 & 3.16 & 3.58 & & \\
TiA End & Lowered & 17 & 3.19 & 0.75 & 2.77 & 3.58 & \multirow{2}{*}{0.06} & 0.38 \\
& Promoted & 20 & 3.24 & 0.53 & 2.99 & 3.49 & & \\
\hline
\end{tabular}

Table 4: TiA descriptive values; HDI = highest density interval.

\begin{tabular}{lccccccccc}
\hline & \multirow{2}{*}{$\alpha$} & \multirow{2}{*}{ Group } & \multirow{2}{*}{$N$} & \multirow{2}{*}{$M$} & \multirow{2}{*}{$S D$} & LL & UL & \multirow{2}{*}{$d$} & \multirow{2}{*}{ BF $_{-0}$} \\
\hline \multirow{2}{*}{ Trust Video } & \multirow{2}{*}{.63} & Lowered & 20 & 3.25 & 0.74 & 2.87 & 3.58 & \multirow{2}{*}{0.07} & \multirow{2}{*}{0.39} \\
& & Promoted & 20 & 3.32 & 0.58 & 3.04 & 3.62 & & \\
\multirow{2}{*}{ Trust Introductory Drive } & \multirow{2}{*}{.70} & Lowered & 20 & 3.25 & 0.70 & 2.93 & 3.53 & \multirow{2}{*}{4.59} & \multirow{2}{*}{4.35} \\
& \multirow{2}{*}{ Trust End } & Promoted & 20 & 3.70 & 0.55 & 3.55 & 4.00 & & \\
& \multirow{2}{*}{.85} & Lowered & 17 & 3.35 & 1.01 & 2.79 & 3.89 & \multirow{2}{*}{0.02} & 0.34 \\
& & Promoted & 20 & 3.38 & 0.87 & 2.99 & 3.82 & & \\
\hline
\end{tabular}

Table 5: Trust subscale descriptive values; HDI = highest density interval. 


\begin{tabular}{|c|c|c|c|c|c|c|c|c|c|}
\hline & \multirow{2}{*}{$\alpha$} & \multirow{2}{*}{ Group } & \multirow{2}{*}{$N$} & \multirow{2}{*}{$M$} & \multirow{2}{*}{$S D$} & \multicolumn{2}{|c|}{ HDI } & \multirow{2}{*}{$d$} & \multirow{2}{*}{$\mathrm{BF}_{-0}$} \\
\hline & & & & & & LL & UL & & \\
\hline \multirow{2}{*}{ Competence Video } & \multirow{2}{*}{.71} & Lowered & 20 & 3.28 & 0.63 & 3.02 & 3.61 & \multirow{2}{*}{0.29} & \multirow{2}{*}{0.90} \\
\hline & & Promoted & 20 & 3.50 & 0.54 & 3.25 & 3.77 & & \\
\hline \multirow{2}{*}{$\begin{array}{l}\text { Competence Introductory } \\
\text { Drive }\end{array}$} & \multirow{2}{*}{.71} & Lowered & 20 & 3.15 & 0.71 & 2.80 & 3.48 & \multirow{2}{*}{0.39} & \multirow{2}{*}{1.49} \\
\hline & & Promoted & 20 & 3.46 & 0.52 & 3.18 & 3.69 & & \\
\hline \multirow{2}{*}{ Competence End } & \multirow{2}{*}{.83} & Lowered & 17 & 3.18 & 0.96 & 2.68 & 3.70 & \multirow{2}{*}{0.05} & \multirow{2}{*}{0.37} \\
\hline & & Promoted & 20 & 3.23 & 0.76 & 2.87 & 3.61 & & \\
\hline
\end{tabular}

Table 6: Competence subscale descriptive values; HDI = highest density interval.
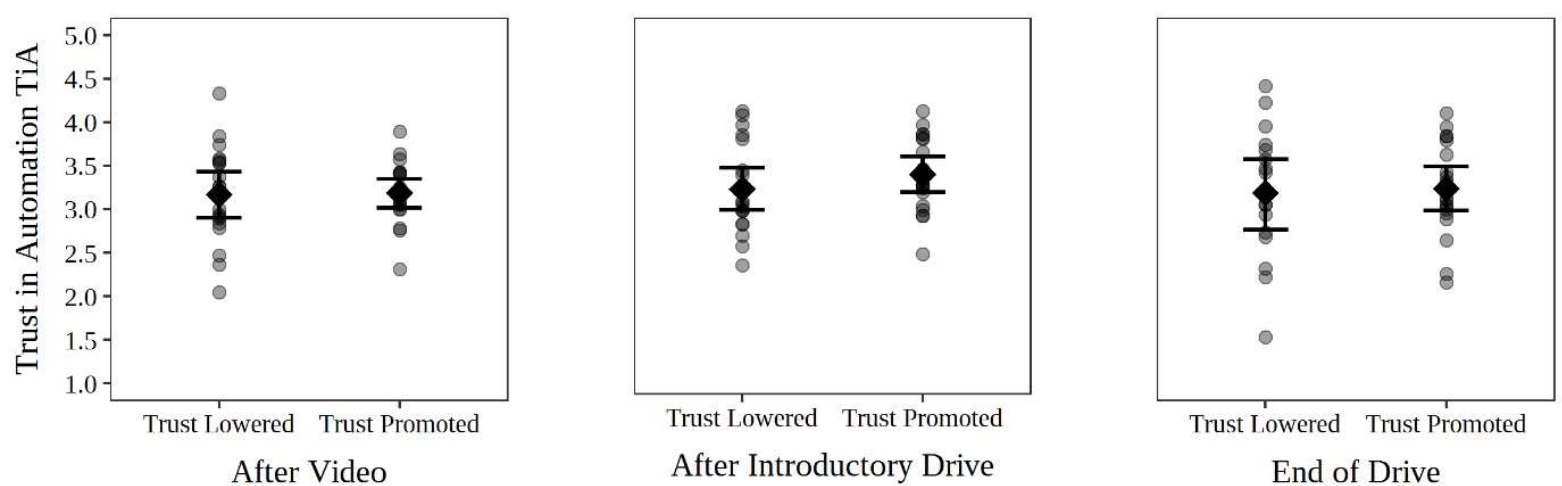

Figure 2: Development of scores of the trust in automation questionnaire TiA; error bars $=95 \%$ HDI.

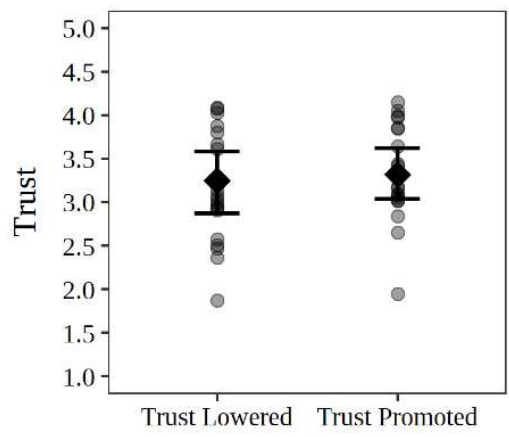

After Video
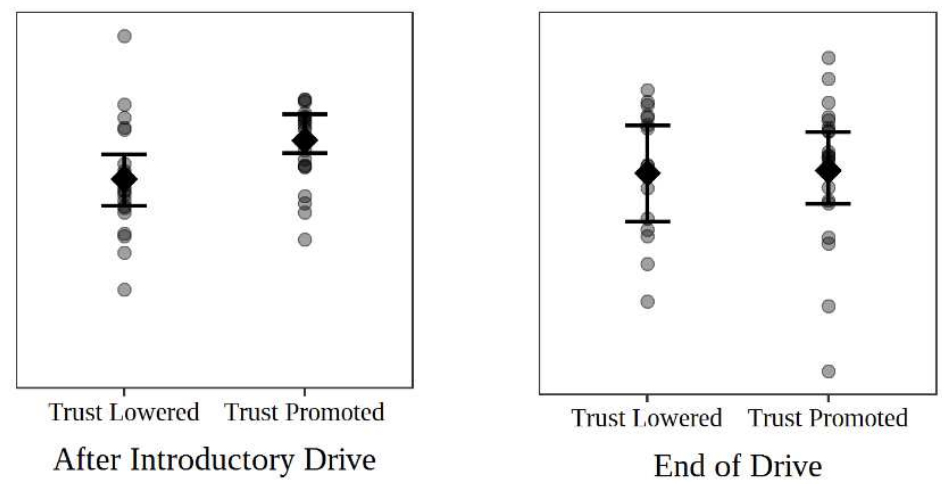

Figure 3: Development of scores of the scale Trust; error bars $=95 \%$ HDI.

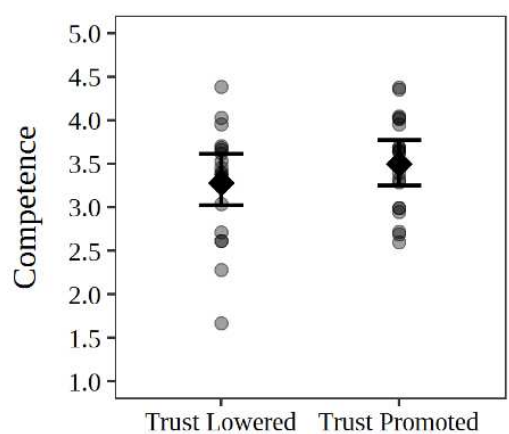

After Video
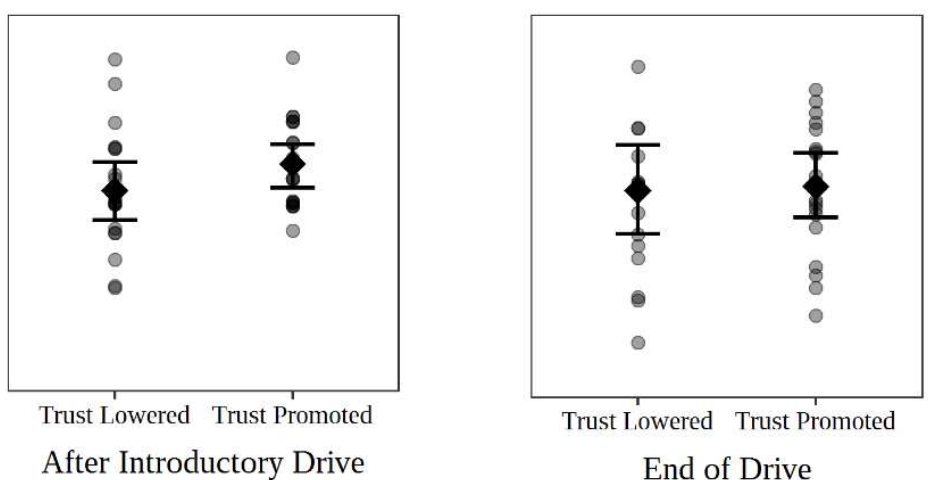

End of Drive

Figure 4: Development of scores of the scale Competence; error bars $=95 \%$ HDI. 


\subsection{Interim 1/Preliminary to Situation 1}

Interim 1 represents the first five minutes of the experimental drive preliminary to Situation 1 . In this time span, the participants were engaged in the NDRT. Tables 7 to 10 report the group differences and correlations between reported trust and gaze behavior on the NDRT or the monitoring gaze behavior respectively. Percentage depicts Percentage of Time on Area of Interest, Frequency depicts Glance Frequency, and Mean depicts Mean Glance Duration.

\begin{tabular}{|c|c|c|c|c|}
\hline & Group & $M$ & $S D$ & $d \quad \mathrm{BF}_{-0}$ \\
\hline Glance & Lowered & 0.55 & 0.11 & \multirow{2}{*}{0.130 .47} \\
\hline Frequency & Promoted & 0.53 & 0.21 & \\
\hline Mean & Lowered & 1.44 & 0.42 & \multirow{2}{*}{0.462 .12} \\
\hline Glance & Promoted & 1.74 & 0.62 & \\
\hline Glance & Lowered & 7.57 & 1.03 & \multirow{2}{*}{0.431 .82} \\
\hline Percentage & Promoted & 8.09 & 0.90 & \\
\hline
\end{tabular}

Table 7: Gaze on NDRT by group; $B F_{+0}$ for frequency, $n=20$.

\begin{tabular}{llccc}
\hline & & Mean & Percentage & Frequency \\
\hline Trust in & $r$ & .10 & .30 & .10 \\
Automation & $\mathrm{BF}$ & 0.34 & 2.01 & 0.13 \\
\multirow{2}{*}{ Trust } & $r$ & .25 & .36 & -.08 \\
& $\mathrm{BF}$ & 1.18 & 4.66 & 0.26 \\
Competence & $r$ & -.01 & .16 & .16 \\
& $\mathrm{BF}$ & 0.19 & 0.53 & 0.11 \\
\hline
\end{tabular}

Table 8: Correlation between gaze on NDRT and subjective trust scales; prior distribution for mean and percentage was $B F+, B F$ - for freauencv: $n=40$.

\begin{tabular}{|c|c|c|c|c|c|c|c|c|c|c|}
\hline & Group & $M$ & $S D$ & $d$ & $\mathrm{BF}_{+0}$ & & & Mean & Percentage & Frequency \\
\hline Glance & Lowered & 0.76 & 0.18 & & & Trust in & $r$ & -.13 & -.40 & -.33 \\
\hline Frequency & Promoted & 0.58 & 0.11 & & 158.61 & Automation & $\mathrm{BF}_{-}$ & 0.42 & 9.67 & 3.19 \\
\hline Mean & Lowered & 0.70 & 0.12 & & & Trust & $r$ & .10 & -.33 & -.40 \\
\hline Glance & Promoted & 0.71 & 0.16 & 0.05 & 0.27 & 1 rust & $\mathrm{BF}_{-}$ & 0.13 & 3.00 & 9.64 \\
\hline $\begin{array}{l}\text { Glance } \\
\text { Percentage }\end{array}$ & $\begin{array}{l}\text { Lowered } \\
\text { Promoted }\end{array}$ & $\begin{array}{l}5.18 \\
4.22\end{array}$ & $\begin{array}{l}1.26 \\
1.03\end{array}$ & 0.69 & 8.32 & Competence & $\begin{array}{l}r \\
\mathrm{BF}_{-}\end{array}$ & $\begin{array}{c}-0.12 \\
0.39\end{array}$ & $\begin{array}{l}-.29 \\
1.76\end{array}$ & $\begin{array}{l}-.23 \\
0.93\end{array}$ \\
\hline
\end{tabular}

Table 9: Monitoring by group; $n=20$.

Table 10: Correlation between monitoring and subjective trust scales; $n=40$.

Table 11 and 12 show the relationship between trust and horizontal standard deviation of gaze, i.e. the scanning behavior.

\begin{tabular}{ccccc}
\hline Group & $M$ & $S D$ & $d$ & $\mathrm{BF}_{+0}$ \\
\hline Horizontal SD & $\begin{array}{l}\text { Lowered 9.97 } \\
\text { Promoted 9.55 }\end{array}$ & 0.19 & 0.59 \\
\hline
\end{tabular}

Table 11: Horizontal standard deviation of gaze by group; $n=20$.

\begin{tabular}{llc}
\hline & & Horizontal SD \\
\hline \multirow{2}{*}{ Trust in Automation } & $r$ & -.33 \\
& $\mathrm{BF}_{-}$ & 3.26 \\
Trust & $r$ & -.28 \\
\multirow{2}{*}{ Competence } & $\mathrm{BF}_{-}$ & 1.65 \\
& $r$ & -.33 \\
& $\mathrm{BF}_{-}$ & 2.92 \\
\hline
\end{tabular}

Table 12: Correlation between trust scales and horizontal standard deviation of gaze; $n=40$.

\subsection{Situation 1}

Situation 1 consisted of a slower-moving truck that was used as an obstacle on the participant's lane. The automated ego vehicle approaches the truck up to a headway distance of 35 meters and then overtakes the truck very closely. It was evaluated, if participants rely on the automated driving system or if they intervene and overtake manually. Table 13 shows the frequency of interventions (= optional takeovers) by group. The relative risk between the groups was $R R=1.60$; the odds ratio estimated with an 
independent multinomial prior with the direction Lowered $<$ Promoted was $O R=3.65$ [0.97, 14.82], $\mathrm{BF}=4.69$. Table 14 shows the type of intervention by group.

\begin{tabular}{|c|c|c|c|c|c|c|c|}
\hline & No intervention & Intervention & Total & & Steering & Braking & Total \\
\hline Lowered & 10 & 10 & 20 & Lowered & 3 & 7 & 10 \\
\hline Promoted & 16 & 4 & 20 & Promoted & 2 & 2 & 4 \\
\hline Total & 26 & 14 & 40 & Total & 5 & 9 & 14 \\
\hline
\end{tabular}

We also compared the trust level of the participants who intervened with the level among the participants who did not intervene. We found evidence for a medium difference in all scales with varying strength of evidence. The results are listed in Table 15. Headway distance values of the $n=14$ participants who intervened have been cleared of outliers by the function out(x) which detects outliers using the Median Absolute Deviation statistic MAD with a cutoff value of 2.24 (Wilcox, 2012). This led to the exclusion of 3 observations, 2 of the group Trust Lowered. Table 16 reports the correlation between headway distance at the time of intervention and reported trust.

\begin{tabular}{|c|c|c|c|c|c|}
\hline & Intervention $N$ & $N$ & $S D$ & $d$ & $\mathrm{BF}_{+0}$ \\
\hline \multirow{2}{*}{$\begin{array}{l}\text { Trust in } \\
\text { Automation }\end{array}$} & No & 263.37 & 0.49 & \multirow{2}{*}{\multicolumn{2}{|c|}{0.411 .51}} \\
\hline & Yes & 143.13 & 0.43 & & \\
\hline \multirow{2}{*}{ Trust } & No & 263.62 & 0.67 & \multirow{2}{*}{\multicolumn{2}{|c|}{0.502 .40}} \\
\hline & Yes & 143.21 & 0.58 & & \\
\hline \multirow{2}{*}{ Competence } & No & 263.41 & 0.69 & \multirow{2}{*}{\multicolumn{2}{|c|}{0.401 .50}} \\
\hline & Yes & 143.10 & 0.46 & & \\
\hline
\end{tabular}

Table 15: Trust scales by intervention.

\begin{tabular}{llc}
\hline & \multicolumn{1}{c}{ Headway distance } \\
\hline Trust in & $r$ & -.37 \\
Automation & $\mathrm{BF}-$ & 1.12 \\
\multirow{2}{*}{ Trust } & $r$ & -.13 \\
& $\mathrm{BF}-$ & 0.51 \\
Competence & $r$ & -.09 \\
& $\mathrm{BF}-$ & 0.45 \\
\hline
\end{tabular}

Table 16: Correlation between trust scales and headway distance at time of intervention; $n=11$.

\subsection{Interim 2/Preliminary to Situation 2}

Interim 2 represents the five-minute long time span between Situation 1 and Situation 2. In this time span, the participants were engaged in the NDRT. Tables 17 to 20 report the correlations between reported trust in the questionnaire and gaze behavior on NDRT or the monitoring gaze behavior respectively. One participant from the Trust Lowered group had to be excluded from the eye tracking analysis beginning with Interim 2 because of data logging problems.

\begin{tabular}{|c|c|c|c|c|c|c|c|c|c|c|}
\hline & Group & $N \quad M$ & $S D$ & $d$ & $\mathrm{BF}_{-0}$ & & & Mean & Percentage & Frequency \\
\hline Glance & Lowered & 190.56 & 0.11 & & & Trust in & $r$ & .16 & .21 & -.01 \\
\hline Frequency & Promoted & 200.51 & 0.25 & 0.23 & 0.69 & Automation & $\mathrm{BF}$ & 0.53 & 0.78 & 0.21 \\
\hline Mean & Lowered & 191.51 & 0.39 & & & Trust & $r$ & .35 & .35 & -.25 \\
\hline Glance & Promoted & 202.13 & 0.86 & & $3.6 /$ & 11ust & BF & 3.81 & 3.87 & 1.14 \\
\hline Glance & Lowered & 198.25 & 1.02 & & & Competence & $r$ & .02 & .12 & .07 \\
\hline Percentage & Promoted & 208.92 & 1.02 & & $3.1 /$ & 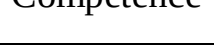 & $\mathrm{BF}$ & 0.22 & 0.38 & 0.15 \\
\hline
\end{tabular}

Table 17: Gaze on the NDRT by group; $B F_{+0}$ for frequency.

Table 18: Correlation between trust scales and gaze on the NDRT; prior distribution for mean and percentage was $B F_{+}, B F-$ for frequency; $n=39$. 


\begin{tabular}{|c|c|c|c|c|c|c|c|c|c|c|c|}
\hline & Group & $N$ & $M$ & $S D$ & $d$ & $\mathrm{BF}_{+0}$ & & & Mean & Percentage & Frequency \\
\hline Glance & Lowered & 19 & 0.61 & 0.21 & & & Trust in & $r$ & -.38 & -.36 & -.34 \\
\hline Frequency & Promoted & 20 & 0.37 & 0.18 & & & Automation & $\mathrm{BF}_{-}$ & 5.92 & 4.64 & 3.23 \\
\hline Mean & Lowered & 19 & 0.73 & 0.11 & & & Trust & $r$ & -.21 & -.39 & -.43 \\
\hline Glance & Promoted & 20 & 0.63 & 0.13 & 0.70 & 8.04 & Irust & $\mathrm{BF}_{-}$ & 0.80 & 7.38 & 15.53 \\
\hline Glance & Lowered & 19 & 4.31 & 1.52 & & ר? & Competence & $r$ & -.34 & -.29 & -.31 \\
\hline Percentage & Promoted & 20 & 2.55 & 1.76 & & & & $\mathrm{BF}_{-}$ & 3.32 & 1.81 & 2.18 \\
\hline
\end{tabular}

Table 19: Monitoring gaze by group.

Table 20: Correlation between monitoring gaze and trust scales; $n=39$.

Tables 21 and 22 show the relationship between trust and horizontal standard deviation gaze, i.e. the scanning behavior.

\begin{tabular}{lcccccc}
\hline & Group & $N$ & $M$ & $S D$ & $d$ & $\mathrm{BF}_{+0}$ \\
\hline Horizontal SD & $\begin{array}{l}\text { Lowered } \\
\text { Promoted } 20\end{array}$ & 8.561 .51 & 1.75 & 0.54 & 3.17 \\
\hline
\end{tabular}

Table 21: Horizontal gaze deviation by group; $n=20$.

\subsection{Situation 2}

Situation 2 represented a critical take-over situation where a take-over by the participant was necessary to avoid a collision. Take-over performance was measured by take-over time (TOT), and take-over quality was measured by minimum TTC (minTTC; distance of front of ego vehicle to obstacle divided by current speed), maximum longitudinal acceleration, maximum lateral acceleration, and involvement in a collision. Table 23 show the frequency of collisions by group. The relative risk between the groups was $R R=13.00$; the odds ratio with an independent multinomial prior (Jamil et al., 2016) with the direction Lowered $<$ Promoted was $O R=13.89$ [1.82, 444.52], $\mathrm{BF}=18.33$. We also compared the trust level of the participants who were involved in a collision with that among the participants who were not involved. The results are listed in Table 24.

\begin{tabular}{|c|c|c|c|c|c|c|c|c|c|c|}
\hline & \multirow[t]{2}{*}{ No collision } & \multirow[t]{2}{*}{ Collision } & \multirow[t]{2}{*}{ Total } & \multirow{3}{*}{$\begin{array}{l}\text { Trust in } \\
\text { Automation }\end{array}$} & Collision & $N$ & \multirow{2}{*}{$\frac{M}{3.57}$} & \multirow{2}{*}{\multicolumn{2}{|c|}{$\begin{array}{cc}S D \quad d \\
0.38\end{array}$}} & \multirow{2}{*}{$\frac{\mathrm{BF}_{+0}}{1.82}$} \\
\hline & & & & & Yes & 6 & & & & \\
\hline Lowered & 20 & 0 & 20 & & No & 34 & 3.23 & 0.48 & 0.51 & 1.82 \\
\hline Promoted & 14 & 6 & 20 & & Yes & 6 & 3.92 & 0.20 & & \\
\hline Total & 34 & 6 & 40 & Trust & No & 34 & 3.40 & 0.68 & 0.50 & 2.34 \\
\hline Table 23: & tent & & & Competence & $\begin{array}{l}\text { Yes } \\
\text { No }\end{array}$ & $\begin{array}{c}6 \\
34 \\
\end{array}$ & $\begin{array}{l}3.78 \\
3.22\end{array}$ & $\begin{array}{l}0.66 \\
0.60\end{array}$ & 0.67 & 3.34 \\
\hline
\end{tabular}

Table 24: Trust scales by collision.

Mean take-over times and minTTC values have been screened for unreasonable high values resulting in the removal of participant 14, 19 and 40 because of unreasonable high values larger than $17 \mathrm{~s}$. We found a difference of $\Delta \mathrm{M}=1154 \mathrm{~ms}$ between the Trust Lowered group $\left(M_{\text {Lowered }}=1.17, S D=1.21\right)$ and the Trust Promoted group $\left(M_{\text {Promoted }}=2.32, S D=1.44\right)$; the $\mathrm{BF}_{10}$ with prior Low $<$ High of $\mathrm{BF}_{10}=10.82$ indicates strong evidence for a difference in means. There was also a difference in minTTC of $\Delta \mathrm{M}=933 \mathrm{~ms}\left(M_{\text {Lowered }}=1.44, S D=1.21 ; M_{\text {Promoted }}=0.50, S D=0.35\right)$ with a $\mathrm{BF}_{10}$ with prior Lowered $>$ Promoted of $\mathrm{BF}_{10}=11.23$, thus strong evidence for a difference. Figures 5 and 6 visualize the difference. 

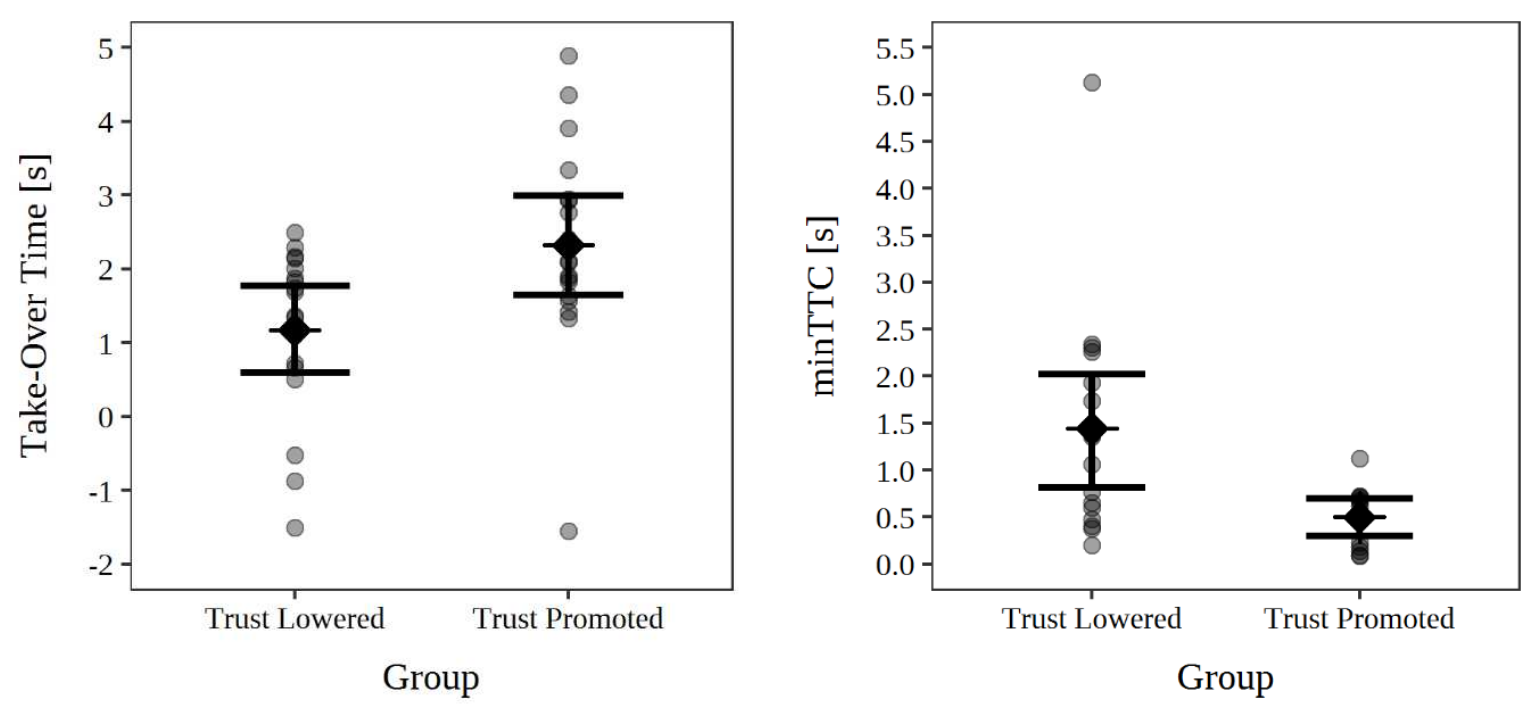

Figure 5: Take-over time by group; error bars $=95 \%$ Figure 6: MinTTC by group; error bars $=95 \%$ HDI . HDI.

Table 26 reports the correlation between reported trust and take-over performance as well as take-over quality. Both measures are also listed by group in Table 25 .

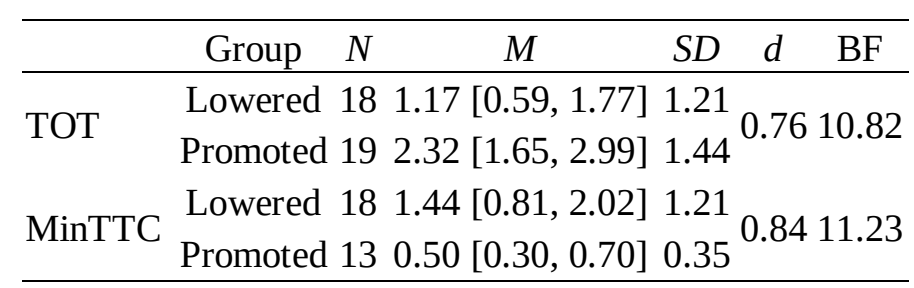

Table 25: TOT and minimum time-to-collision (minTTC) by group; $95 \%$ HDI in brackets; prior for TOT was BF-o and $B F+0$ for minTTC.

\begin{tabular}{lcccc}
\hline & \multicolumn{2}{c}{ TOT } & \multicolumn{2}{c}{ minTTC } \\
& $r$ & $\mathrm{BF}_{+}$ & $r$ & $\mathrm{BF}_{-}$ \\
\hline Trust in & .27 & 1.41 & -.29 & 1.34 \\
Automation & .25 & & & \\
Trust & .33 & 2.54 & -.35 & 2.49 \\
Competence & .24 & 1.02 & -.21 & 0.70 \\
\hline
\end{tabular}

Table 26: Correlation between trust scales and TOT and minimum time-to-collision (minTTC); $n_{\text {TOT }}=37 ; n_{\min T T C}=31$.

Next, we analyzed the take-over quality measures maximum longitudinal acceleration and maximum lateral acceleration. Tables 27 and 28 show the correlations between trust and take-over quality as well as take-over quality by group.

\begin{tabular}{|c|c|c|c|c|c|}
\hline \multirow{3}{*}{ 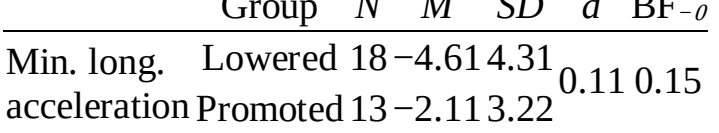 } & & \multirow{2}{*}{\multicolumn{2}{|c|}{$\begin{array}{l}\text { Min. long. } \\
\text { acceleration }\end{array}$}} & \multirow{2}{*}{\multicolumn{2}{|c|}{$\begin{array}{l}\text { Max. } \\
\text { lat. acceleration }\end{array}$}} \\
\hline & & & & & \\
\hline & & $r$ & $\mathrm{BF}_{-}$ & $r$ & $\mathrm{BF}_{+}$ \\
\hline \multirow{3}{*}{$\begin{array}{l}\text { Max. lat. Lowered } 182.851 .57 \\
\text { acceleration Promoted } 133.181 .69\end{array}$} & Trust in Automation & .28 & 0.10 & -.15 & 0.13 \\
\hline & Trust & .32 & 0.09 & -.12 & 0.15 \\
\hline & Competence & .19 & 0.12 & -.20 & 0.12 \\
\hline
\end{tabular}
max. lat. acceleration are absolute Table 28: Correlation between take-over quality and trust values. scales; $n=31$. 


\subsection{Interim 3/Preliminary to Situation 3}

Interim 3 represents the five-minute long time span between Situation 2 and Situation 3. In this time span, the participants were engaged in the NDRT. Tables 29 to 32 report the correlations between reported trust in the questionnaire and gaze behavior on NDRT or the monitoring gaze behavior respectively.

\begin{tabular}{|c|c|c|c|}
\hline & Group $N \quad M$ & $S D$ & $d \quad \mathrm{BF}_{-\mathrm{c}}$ \\
\hline Glance & Lowered 160.60 & 0.17 & \\
\hline Frequency & Promoted 200.60 & 0.25 & \\
\hline Mean & Lowered 161.48 & 0.58 & \\
\hline Glance & Promoted 201.74 & 0.82 & \\
\hline Glance & Lowered 168.33 & 1.03 & 0.2 \\
\hline Percentag & e Promoted 208.65 & 1.17 & \\
\hline
\end{tabular}

Table 29: Correlation between trust scales and gaze on NDRT; $B F+o$ for frequency.

\begin{tabular}{llccc}
\hline & & Mean & Percentage & Frequency \\
\hline Trust in & $r$ & .19 & .31 & -.07 \\
Automation & $\mathrm{BF}$ & 0.66 & 1.95 & 0.29 \\
\multirow{2}{*}{ Trust } & $r$ & .23 & .34 & -.14 \\
& $\mathrm{BF}$ & 0.91 & 3.04 & 0.45 \\
Competence & $r$ & .15 & .28 & -.07 \\
& $\mathrm{BF}$ & 0.49 & 1.52 & 0.30 \\
\hline
\end{tabular}

Table 30: Correlation between trust scales and gaze on the NDRT; prior distribution for mean and percentage was $B F_{+}, B F-$ for frequency; $n=36$.

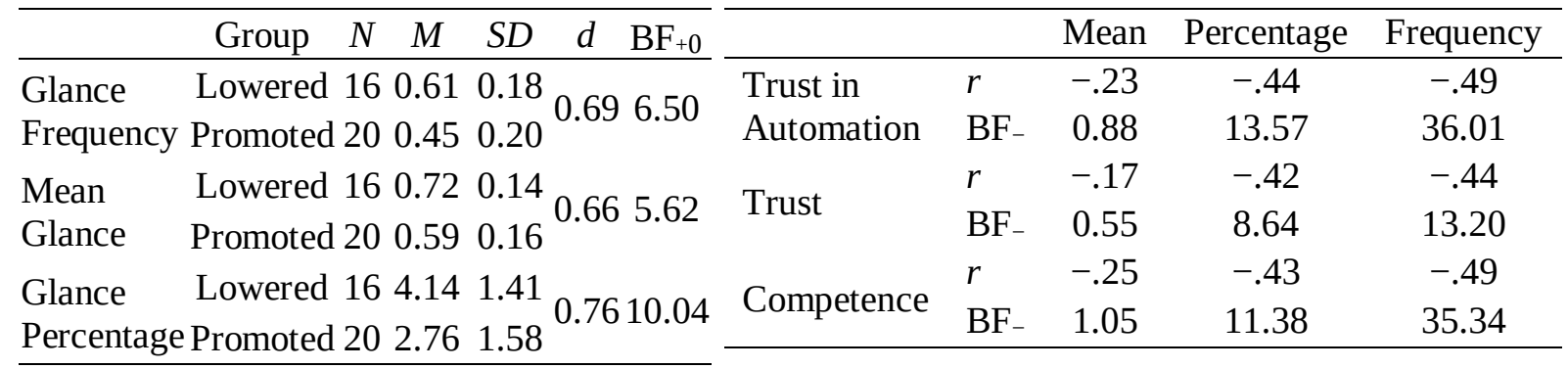

Table 31: Correlation between trust scales and Table 32: Monitoring gaze by group; $n=36$. monitoring gaze; prior distribution for mean and percentage was $\mathrm{BF}_{+}, \mathrm{BF}$ - for frequency.

Tables 33 and 34 show the relationship between trust and horizontal standard deviation gaze, i.e. the scanning behavior.

\begin{tabular}{rccccc}
\hline Group & $N$ & $M$ & $S D$ & $d$ & $\mathrm{BF}_{+0}$ \\
\hline Horizontal SD & $\begin{array}{l}\text { Lowered 169.33 } \\
\text { Promoted 20 8.87 }\end{array}$ & & & & \\
& 0.20 & 0.62 \\
\hline
\end{tabular}

Table 33: Standard deviation of horizontal gaze by group.

\begin{tabular}{llc}
\hline & & Horizontal SD \\
\hline \multirow{2}{*}{ Trust in Automation } & $r$ & -.38 \\
& $\mathrm{BF}_{-}$ & 4.70 \\
\multirow{2}{*}{ Trust } & $r$ & -.34 \\
\multirow{2}{*}{ Competence } & $\mathrm{BF}_{-}$ & 3.01 \\
& $r$ & -.41 \\
\hline
\end{tabular}

Table 34: Correlation between trust scales and SD of horizontal gaze; $n=36$.

\subsection{Situation 3}

Situation 3 was similar to Situation 1 in the sense that it was a close, but non-critical situation without an obligatory take-over. The ACC system did not adapt to the lower speed of a slower-moving truck ahead and, therefore, the ego vehicle approached the truck up to a distance of 35 meters, at which point the ACC was activated again. Thus, a take-over was not necessary but participants who did not trust in the automated driving system were expected to brake before the ACC was reactivated in order to solve the situation manually. Three participants had to be excluded because of data logging problems. Table 35 shows the frequency of interventions (= optional take-overs) by group. The relative risk between the 
groups was $R R=2.94$; the odds ratio with an independent multinomial prior with the direction Lowered $<$ Promoted was $O R=5.01$ [1.32, 21.63], $\mathrm{BF}=12.90$. Table 36 shows the type of intervention by group.

\begin{tabular}{lccc}
\hline & No intervention & Intervention & Total \\
\hline Lowered & $7(35.29 \%)$ & $10(64.71 \%)$ & 17 \\
Promoted & $16(70.00 \%)$ & $4(30.00 \%)$ & 20 \\
\hline Total & 23 & 14 & 37 \\
\hline
\end{tabular}

Table 35: Intervention by group.

\begin{tabular}{lcccc}
\hline & Steering & Braking & Accelerating & Total \\
\hline Lowered & 2 & 8 & 1 & 11 \\
Promoted & 5 & 1 & 0 & 6 \\
\hline Total & 7 & 9 & 1 & 17 \\
\hline
\end{tabular}

Table 36: Type of intervention by group.

We also compared the trust level of the participants who intervened with that among the participants who did not intervene. We found evidence for a medium difference in the TiA scales as well as in Trust. The results are listed in Table 37. Headway distance values have been again cleared of outliers considering the MAD. This led to the exclusion of three observations from the group Trust Lowered who intervened at a distance of over $127 \mathrm{~m}$. Table 38 reports the correlation between headway distance at the time of intervention and reported trust.

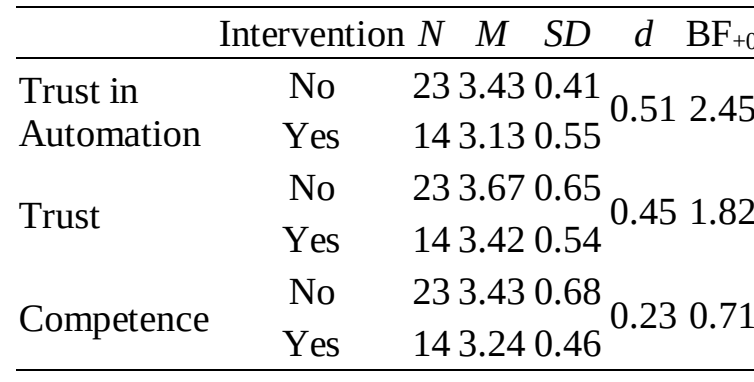

Table 37: Trust scores by intervention.

\begin{tabular}{llc}
\hline & & Headway distance \\
\hline \multirow{2}{*}{ Trust in Automation } & $r$ & -.23 \\
& $\mathrm{BF}-$ & 0.68 \\
Trust & $r$ & -.12 \\
& $\mathrm{BF}-$ & 0.49 \\
Competence & $r$ & -.03 \\
& $\mathrm{BF}_{-}$ & 0.39 \\
\hline
\end{tabular}

Table 38: Correlation between trust scales and headway distance at point of intervention; $n=11$.

After the experimental drive, the participants filled out the TiA questionnaire for a third and last time after their experimental drive. Figures 2 to 4 visualize the development of reported trust at the three measurements.

\section{Discussion}

In this study, we investigated the relationship between subjective trust in automation, manipulated by prior introductory information and experience, and reliance behavior in automated driving. The experimental setup consisted of a highway drive with an SAE Level 3 automated vehicle with engagement in an NRDT. The participants encountered three traffic situations: Situation 1 and 3 were non-critical situations that are solved by the automated driving system and a take-over was not obligatory or requested but is a reasonable action if one does not trust the automated driving system. Situation 2 represented a critical situation that required a take-over by the driver to avoid a collision with an obstacle.

The first goal of this study was to investigate whether trust can be manipulated by prior information. We divided the participants into two groups (Trust Lowered and Trust Promoted) that received either trust-lowering or trust-promoting information prior to the experimental drive. Trust was measured by a questionnaire at the beginning, after the introductory drive, and at the end of the experiment. We found no evidence for a difference between the groups in the measurement after the video - this manipulation 
alone was probably not strong enough to influence the ratings. However, we found sufficient evidence for higher scores in Trust and Competence in the Trust Promoted group after the introductory drive. In the trust measurement after the experimental drive, participants reported equal trust levels for all trust scales. It seems that trust has been calibrated by experience for both groups and the initial introductory information has had no impact on trust ratings anymore.

To record the allocation of attention between an NDRT and the traffic situation, we implemented interim experimental stages (Interim 1-3) preliminary to each situation in which the participants should engage in an NDRT. We consistently found the same gaze patterns in all three interim stages with slightly varying strength of the relationships: With increasing trust, participants looked at the NDRT for a longer time ( $r=.34$ to .35) and looked at the road and instrument cluster for less time $(r=-.33$ to -.42$)$ and fewer times $(r=-.40$ to -.44$)$. This relationship was also found on the group level, i.e. the Trust Promoted group looked at the NDRT for a longer time, while having a lower glance frequency and glance percentage on the road and instrument cluster. Contrary to a previous study (Gold, Körber, Hohenberger, Lechner, \& Bengler, 2015), participants with higher trust scanned the environment less. This relationship could not be found regarding the difference between both groups except in Interim 2. Thus, individual trust does not completely determined by prior information but both the initial trust level and the change in trust level by prior information depend on stable individual differences in the propensity to trust automated systems (Lee \& See, 2004). Accordingly, Merritt and Ilgen (2008) found that a user's individual perception of automation is not completely determined by the actual machine characteristics but also depends on the individual user's propensity to trust machines.

We implemented two situations (Situation 1 and 3) that were solved by the automated driving system but a take-over was a reasonable action if one did not trust the system. In Situation 1, ten participants (50\%) of the Trust Lowered group compared to four participants of the Trust Promoted group (20\%) intervened, i.e. distrusted and did not rely on the automated driving system. The participants who intervened differed moderately from non-intervening participants in their reported trust. The sample size was too small to conclusively evaluate if there is a small correlation between reported trust and headway distance at intervention. In Situation 3, the odds to intervene of participants in the Trust Lowered group were five times higher than participants in the Trust Promoted group: ten participants (65 \%) of the Trust Lowered group compared to four participants (30 \%) intervened. Participants who intervened also had reported moderately higher trust scores, but no relationship between trust and time of intervention was found. Hence, the trust influencing prior information did not only influence subjective trust ratings but also reliance on the automated driving system as the Trust lowered group relied less on the automated driving system.

Situation 2 represented a critical take-over situation, in which participants had to intervene to avoid a collision. Six participants in the Trust Promoted group compared to zero participants in the Trust Lowered group collided with the obstacle. Participants who collided also reported higher trust scores with a large difference to non-colliders. Regarding take-over performance, as expected, participants of the Trust Promoted group took 1154 ms longer to take-over vehicle control compared to the Trust Lowered group. Regarding take-over quality, there was also strong evidence for a difference in minTTC of 933 ms, i.e. participants of the Trust Promoted group executed a more critical take-over maneuver. Higher reported trust was associated with a higher TOT and a lower minTTC. We found slight evidence for higher minimum longitudinal accelerations in the Trust Lowered group, however, no participant was involved in a collision in this group. We found no difference in maximum lateral accelerations.

\subsection{Conclusion}

We found that trust levels influence the interaction with an automated driving system when an NDRT is present. As expected, participants reporting a higher level of trust spent less time looking at both the road and the instrument cluster, and more time looking at the NDRT. Beyond this, we demonstrated that 
the level of trust also influences behavioral outcomes. Participants reporting lower trust levels were more likely to mistrust the automated driving system and to intervene in Situation 1 and 3. Also, a higher trust level was related to a higher number of collisions, a higher take-over time and a lower minTTC in the obligatory take-over situation (Situation 2). We furthermore demonstrated that prior information influences the reported trust in automation and subsequently the reliance on the automated driving system. Consistent with reported trust, participants in the Trust Promoted group spent less time looking at both the road and the instrument cluster, and more time looking at the NDRT. In the critical take-over situation, Situation 2, the mean TOT was extended by $1154 \mathrm{~ms}$ and mean minTTC was 933 ms lower in the Trust Promoted group. The collision of six participants in the Trust Promoted group compared to zero participants in the Trust Lowered group highlights the safety-relevance of the deterioration of takeover performance caused by over-trust. In conclusion, we demonstrated that the individual trust level influences how much drivers monitor the environment while being engaged with an NDRT. The provision of prior information influences this trust level, reliance on an automated driving system, and also if a critical take-over situation can be successfully solved. The results hereby empirically confirm the theoretical predictions and transfer the knowledge on individual differences in the interaction with automation to the field of conditional automated driving.

\subsection{Limitations}

The results of this study have certain limitations in their evidential value and potential for generalization. The study was conducted in a driving simulator because of the given risk of collisions and injuries. It is conceivable, therefore, that participants may have behaved in a riskier manner in this setup because of the lack of consequences. We conducted the experiment in a high fidelity mockup with a realistic scenario for the deployment of driving automation and therefore believe that participants' immersion was sufficient to ensure realistic behavior. The sample size of 40 participants in this experiment was small. Since our results are in accordance with previous results, we believe that our conclusions are nonetheless valid, however, we recommend a large sample size for a more exact parameter estimation and for future confirmatory work. Also, since age has been shown to be relevant for trust in automation (Gold et al., 2015; Wiegmann, McCarley, Kramer, \& Wickens, 2006), a more diverse sample regarding age should be chosen. The measurement of trust by questionnaires and its relationship to behavioral measures has yet to be investigated psychometrically in further detail. Additional work in this area might result in the confirmation of stronger relationships. To reduce measurement error further, a different eye tracking system than Dikablis should be used, which seems to provide data in insufficient accuracy in certain situations (Hergeth et al., 2016). For example, the correlations regarding monitoring are stronger and more consistent than the correlations regarding the NDRT because the AOI for monitoring was easier to detect. A different eye tracking system could increase the amount and consistency of the evidence we found for the hypotheses in this study.

\subsection{Practical application and future work}

Since six participants of the Trust Promoted group compared to zero of the Trust Lowered group collided with the obstacle, the results show the safety benefits of appropriately calibrated trust. Because prior information material systematically influenced participants' trust in automation in this study, car manufacturers should carefully consider how they introduce an automated driving system to customers. A focus on the automated driving system's competence without an appropriate elaboration of its limitations might lead to miscalibrated trust, at least with little further experience. The aforementioned Tesla accident showed that albeit all necessary information on Tesla's Autopilot was provided by the company, dramatic overreliance ensued (Office of Defects Investigations, 2017). At the same time, participants of the Trust lowered group showed signs of automation disuse by their unnecessary intervention. 
Future users of automated vehicles will not be experts but laypersons without in-depth knowledge of the driving automation (Walker et al., 2016). Hence, they will at the beginning build themselves a mental model of its functioning based on either information provided with the system or interactions with it (Naujoks \& Totzke, 2014). Beggiato, Pereira, Petzoldt, and Krems (2015) pointed out that a correct mental model of the functioning and limits of an automated driving system are crucial for the transfer and application of knowledge in different traffic situations. Without correct and comprehensible feedback, an incorrect mental model might be constructed (Christofferson \& Woods, 2002). Customer-tailored training and information material to introduce automated driving have to be developed to appropriately calibrate trust and to mitigate the negative effects of automation failure, especially in the event of the first failure that occurs (Wickens \& Xu, 2002). Such a training should emphasize how particular situations interact with the characteristics of the automated driving system to influence its capability to solve a situation (Lee \& See, 2004). A driver training also should explain the system's behavior, point out invisible limitations, and explain the driving automation's functioning. Drivers could be encouraged to think aloud in such a training to disclose any flaws in their mental model. Beyond this, a calibration of trust by visualizing the automated driving system's confidence could continue to ensure appropriate reliance in long-term use. This information may be provided by a color-coded visual scale, anthropomorphic symbols or emoticons in either the instrument cluster or a head-up display (Beller et al., 2013; Helldin et al., 2013; Seppelt \& Lee, 2007). A human-machine interface (HMI) could also by request give a verbal or visual explanation of a system limit directly after its occurrence to promote the understanding of the automated driving system's intentions, limits, and actions. Future research could focus on the optimal communication of the automated driving system's status and intentions in an informative way without being distractive or annoying. It may furthermore be possible to implement a gamification approach and to apply typical game-design elements for the purpose of forming behavior (Robson, Plangger, Kietzmann, McCarthy, \& Pitt, 2015).

\section{References}

Abe, G., Itoh, M., \& Tanaka, K. (2002). Dynamics of drivers' trust in warning systems. In L. Basañez (Ed.): IFAC proceedings volumes, Proceedings of the 15th Triennial World Congress of the International Federation of Automatic Control (pp. 363-368). New York, NY: Elsevier. https://doi.org/10.3182/20020721-6-ES-1901.01614

Ajzen, I., \& Fishbein, M. (1980). Understanding attitudes and predicting social behavior. Englewood Cliffs NJ: Prentice Hall.

Bagheri, N., \& Jamieson, G. A. (2004). Considering subjective trust and monitoring behavior in assessing automation-induced "complacency". In D. A. Vincenzi, M. Mouloua, \& P. A. Hancock (Eds.), Human performance, situation awareness, and automation. Current research and trends HPSAA II, volumes I and II (Vol. 1, pp. 54-59). Mahwah, NJ: Lawrence Erlbaum Associates Inc.

Bahner, J. E., Hüper, A.-D., \& Manzey, D. (2008). Misuse of automated decision aids: Complacency, automation bias and the impact of training experience. International Journal of Human-Computer Studies, 66(9), 688-699. https://doi.org/10.1016/j.ijhcs.2008.06.001

Bailey, N. R., \& Scerbo, M. W. (2007). Automation-induced complacency for monitoring highly reliable systems: The role of task complexity, system experience, and operator trust. Theoretical Issues in Ergonomics Science, 8(4), 321-348. https://doi.org/10.1080/14639220500535301

Barg-Walkow, L. H., \& Rogers, W. A. (2016). The effect of incorrect reliability information on expectations, perceptions, and use of automation. Human Factors: The Journal of the Human Factors and Ergonomics Society, 58(2), 242-260. https://doi.org/10.1177/0018720815610271

Beggiato, M., \& Krems, J. F. (2013). The evolution of mental model, trust and acceptance of adaptive cruise control in relation to initial information. Transportation Research Part F: Traffic Psychology and Behaviour, 18, 47-57. https://doi.org/10.1016/j.trf.2012.12.006 
Beggiato, M., Pereira, M., Petzoldt, T., \& Krems, J. F. (2015). Learning and development of trust, acceptance and the mental model of ACC. A longitudinal on-road study. Transportation Research Part F: Traffic Psychology and Behaviour, 35, 75-84. https://doi.org/10.1016/j.trf.2015.10.005

Beller, J., Heesen, M., \& Vollrath, M. (2013). Improving the driver-automation interaction: An approach using automation uncertainty. Human Factors: The Journal of the Human Factors and Ergonomics Society, 55(6), 1130-1141. https://doi.org/10.1177/0018720813482327

Biassoni, F., Ruscio, D., \& Ciceri, R. (2016). Limitations and automation. The role of information about device-specific features in ADAS acceptability. Safety Science, 85, 179-186. https://doi.org/10.1016/j.ssci.2016.01.017

Carlson, M. S., Drury, J. L., Desai, M., Kwak, H., \& Yanco, H. A. (2014). Identifying factors that influence trust in automated cars and medical diagnosis systems. In 2014 AAAI Spring Symposium Series. The Intersection of Robust Intelligence and Trust in Autonomous Systems (pp. 20-27). Palo Alto, California.

Carsten, O., Lai, F., Barnard, Y., Jamson, A. H., \& Merat, N. (2012). Control task substitution in semiautomated driving: Does it matter what aspects are automated? Human Factors: The Journal of the Human Factors and Ergonomics Society, 54(5), 747-761. https://doi.org/10.1177/0018720812460246

Casner, S. M., Hutchins, E. L., \& Norman, D. A. (2016). The challenges of partially automated driving. Communications of the ACM, 59(5), 70-77. https://doi.org/10.1145/2830565

Choi, J. K., \& Ji, Y. G. (2015). Investigating the importance of trust on adopting an autonomous vehicle. International Journal of Human-Computer Interaction, 31(10), 692-702. https://doi.org/10.1080/10447318.2015.1070549

Christofferson, K., \& Woods, D. D. (2002). How to make automated systems team players. In E. Salas (Ed.), Advances in Human Performance and Cognitive Engineering Research: Vol. 2. Advances in human performance and cognitive engineering research. Automation (1st ed., Vol. 2, pp. 1-12). Amsterdam, Boston: JAI. https://doi.org/10.1016/S1479-3601(02)02003-9

Creaser, J. I., \& Fitch, G. M. (2015). Human factors considerations for the design of Level 2 and Level 3 automated vehicles. In G. Meyer \& S. Beiker (Eds.), Lecture Notes in Mobility. Road Vehicle Automation 2 (pp. 81-89). Cham: Springer International Publishing.

Dienes, Z. (2011). Bayesian versus orthodox statistics: Which side are you on? Perspectives on Psychological Science, 6(3), 274-290. https://doi.org/10.1177/1745691611406920

Dzindolet, M. T., Peterson, S. A., Pomranky, R. A., Pierce, L. G., \& Beck, H. P. (2003). The role of trust in automation reliance. International Journal of Human-Computer Studies, 58(6), 697-718. https://doi.org/10.1016/S1071-5819(03)00038-7

European Commission. (2016). 2015 road safety statistics: What is behind the figures? (MEMO No. 16/864). Brüssel. Retrieved from European Commission website: http://europa.eu/rapid/press-release_MEMO-16-864_en.htm

Feuerberg, B. V., Bahner, J. E., \& Manzey, D. (2005). Interindividuelle Unterschiede im Umgang mit Automation - Entwicklung eines Fragebogens zur Erfassung des Complacency-Potentials [Interindividual differences in the interaction with automation - Development of a questionnaire to assess potential for complacency]. In L. Urbas \& C. Steffens (Eds.), Zustandserkennung und Systemgestaltung. 6. Berliner Werkstatt Mensch-Maschine-Systeme. (pp. 199-202). Düsseldorf: VDI-Verlag.

Gefen, D., Karahanna, E., \& Straub, D. W. (2003). Trust and TAM in online shopping: An integrated model. MIS Quarterly, 27(1), 51-90.

Ghazizadeh, M., Lee, J. D., \& Boyle, L. N. (2012). Extending the Technology Acceptance Model to assess automation. Cognition, Technology \& Work, 14(1), 39-49. https://doi.org/10.1007/s10111011-0194-3 
Gold, C., \& Bengler, K. (2014). Taking over control from highly automated vehicles. In N. A. Stanton, S. Landry, G. Di Bucchianico, \& A. Vallicelli (Eds.): Vol. [8]. Advances in human factors and ergonomics 2014, Advances in human aspects of transportation, Part II (pp. 64-69). Louisville, KY: AHFE Conference.

Gold, C., Körber, M., Hohenberger, C., Lechner, D., \& Bengler, K. (2015). Trust in automation - Before and after the experience of take-over scenarios in a highly automated vehicle. Procedia Manufacturing, 3, 3025-3032. https://doi.org/10.1016/j.promfg.2015.07.847

Grissom, R. J., \& Kim, J. J. (2012). Effect sizes for research: Univariate and multivariate applications (2nd ed.). New York: Routledge.

Helldin, T., Falkman, G., Riveiro, M., \& Davidsson, S. (2013). Presenting system uncertainty in automotive UIs for supporting trust calibration in autonomous driving. In J. Terken (Ed.), Proceedings of the 5th International Conference on Automotive User Interfaces and Interactive Vehicular Applications (pp. 210-217). New York, NY: ACM. https://doi.org/10.1145/2516540.2516554

Hergeth, S., Lorenz, L., Vilimek, R., \& Krems, J. F. (2016). Keep your scanners peeled: Gaze behavior as a measure of automation trust during highly automated driving. Human Factors: The Journal of the Human Factors and Ergonomics Society, 58(3), 509-519.

https://doi.org/10.1177/0018720815625744

Hoff, K. A., \& Bashir, M. (2015). Trust in automation: Integrating empirical evidence on factors that influence trust. Human Factors: The Journal of the Human Factors and Ergonomics Society, 57(3), 407-434. https://doi.org/10.1177/0018720814547570

Horberry, T., Anderson, J., Regan, M. A., Triggs, T. J., \& Brown, J. (2006). Driver distraction: The effects of concurrent in-vehicle tasks, road environment complexity and age on driving performance. Accident Analysis \& Prevention, 38(1), 185-191. https://doi.org/10.1016/j.aap.2005.09.007

ISO 14198. (2012). PD ISO/TS 14198:2012 - Road vehicles - Ergonomic aspects of transport information and control systems - Calibration tasks for methods which assess driver demand due to the use of in-vehicle systems: BSI.

ISO 15007-1 (2014, November 1). Road vehicles - Measurement of driver visual behaviour with respect to transport information and control systems - Part 1: Definitions and parameters. (ISO, 15007-1).

Jamil, T., Ly, A., Morey, R. D., Love, J., Marsman, M., \& Wagenmakers, E.-J. (2016). Default "Gunel and Dickey" Bayes factors for contingency tables. Behavior research methods. Advance online publication. https://doi.org/10.3758/s13428-016-0739-8

Keller, D., \& Rice, S. (2009). System-wide versus component-specific trust using multiple aids. The Journal of General Psychology, 137(1), 114-128. https://doi.org/10.1080/00221300903266713

Körber, M. (2015). Vertrauen in Automation [Trust in automation]. Retrieved from http://www.lfe.mw.tum.de/wp-content/uploads/2016/08/Vertrauen_In_Automation.pdf

Körber, M., \& Bengler, K. (2014). Potential individual differences regarding automation effects in automated driving. In C. S. G. González, C. C. Ordóñez, \& H. Fardoun (Eds.), Interacción 2014: Proceedings of the XV International Conference on Human Computer Interaction (pp. 152-158). New York, NY, USA: ACM. https://doi.org/10.1145/2662253.2662275

Körber, M., Gold, C., Lechner, D., \& Bengler, K. (2016). The influence of age on the take-over of vehicle control in highly automated driving. Transportation Research Part F: Traffic Psychology and Behaviour, 39, 19-32. https://doi.org/10.1016/j.trf.2016.03.002

Körber, M., Radlmayr, J., \& Bengler, K. (2016). Bayesian highest density intervals of take-over times for highly automated driving in different traffic densities. In Proceedings of the Human Factors and Ergonomics Society (HFES) 60th Annual Meeting 2016 (Vol. 60, pp. 2009-2013). https://doi.org/10.1177/1541931213601457 
Kruschke, J. K. (2015). Doing Bayesian data analysis: A tutorial with R, JAGS, and Stan (2. ed.). San Diego, CA: Academic Press.

Lee, J. D., \& Moray, N. (1992). Trust, control strategies and allocation of function in human-machine systems. Ergonomics, 35(10), 1243-1270. https://doi.org/10.1080/00140139208967392

Lee, J. D., \& Moray, N. (1994). Trust, self-confidence, and operators' adaptation to automation. International Journal of Human-Computer Studies, 40(1), 153-184. https://doi.org/10.1006/ijhc.1994.1007

Lee, J. D., \& See, K. A. (2004). Trust in automation: Designing for appropriate reliance. Human Factors: The Journal of the Human Factors and Ergonomics Society, 46(1), 50-80. https://doi.org/10.1518/hfes.46.1.50_30392

Lee, M. D., \& Wagenmakers, E.-J. (2013). Bayesian cognitive modeling: A practical course. Cambridge: Cambridge University Press.

Llaneras, R., Salinger, J., \& Green, C. (2013). Human factors issues associated with limited ability autonomous driving systems: Drivers' allocation of visual attention to the forward roadway. In Proceedings of the 7th International Driving Symposium on Human Factors in Driver Assessment, Training, and Vehicle Design (pp. 92-98). Iowa City, Iowa: The University of Iowa, Public Policy Center.

Love, J., Selker, R., Verhagen, J., Marsman, M., Gronau, Q. F., Jamil, T.,. . Rouder, J. N. (2015). Software to Sharpen Your Stats. APS Observer, 28(3), 27-29.

Ly, A., Verhagen, J., \& Wagenmakers, E.-J. (2016). Harold Jeffreys’s default Bayes factor hypothesis tests: Explanation, extension, and application in psychology. Journal of Mathematical Psychology, 72, 19-32. https://doi.org/10.1016/j.jmp.2015.06.004

Madhavan, P., \& Wiegmann, D. A. (2005). Cognitive anchoring on self-generated decisions reduces operator reliance on automated diagnostic aids. Human Factors: The Journal of the Human Factors and Ergonomics Society, 47(2), 332-341. https://doi.org/10.1518/0018720054679489

Mahr, A., \& Müller, C. (2011). A schema of possible negative effects of advanced driver assistant systems. In Proceedings of the 6th International Driving Symposium on Human Factors in Driver Assessment, Training, and Vehicle Design (pp. 116-121). Iowa City, Iowa: The University of Iowa, Public Policy Center.

Maurer, M., Gerdes, J. C., Lenz, B., \& Winner, H. (2015). Autonomes Fahren: Technische, rechtliche und gesellschaftliche Aspekte [Autonomous driving: Technical, legal, and societal aspects]. Berlin: Springer Vieweg.

Mayer, A. K., Rogers, W. A., \& Fisk, A. D. (2009). Understanding technology acceptance: Effects of user expectancies on human-automation interaction (Technical Report HFA-TR-09-07). Atlanta, GA.

Mayer, A. K., Sanchez, J., Fisk, A. D., \& Rogers, W. A. (2006). Don't let me down: The role of operator expectations in human-automation interaction. Proceedings of the Human Factors and Ergonomics Society Annual Meeting, 50(21), 2345-2349. https://doi.org/10.1177/154193120605002110

Mayer, R. C., Davis, J. H., \& Schoorman, F. D. (1995). An integrative model of organizational trust. Academy of Management Review, 20(3), 709-734. https://doi.org/10.5465/AMR.1995.9508080335

McGuirl, J. M., \& Sarter, N. B. (2006). Supporting trust calibration and the effective use of decision aids by presenting dynamic system confidence information. Human Factors: The Journal of the Human Factors and Ergonomics Society, 48(4), 656-665. https://doi.org/10.1518/001872006779166334

Merritt, S. M., \& Ilgen, D. R. (2008). Not all trust is created equal: Dispositional and history-based trust in human-automation interactions. Human Factors: The Journal of the Human Factors and Ergonomics Society, 50(2), 194-210. https://doi.org/10.1518/001872008X288574 
Meyer, J. (2001). Effects of warning validity and proximity on responses to warnings. Human Factors: The Journal of the Human Factors and Ergonomics Society, 43(4), 563-572. https://doi.org/10.1518/001872001775870395

Meyer, J. (2004). Conceptual issues in the study of dynamic hazard warnings. Human Factors: The Journal of the Human Factors and Ergonomics Society, 46(2), 196-204.

Morey, R. D., \& Rouder, J. N. (2015). BayesFactor: Computation of Bayes factors for common designs. Retrieved from https://CRAN.R-project.org/package=BayesFactor

Muir, B. M., \& Moray, N. (1996). Trust in automation. Part II. Experimental studies of trust and human intervention in a process control simulation. Ergonomics, 39(3), 429-460. https://doi.org/10.1080/00140139608964474

Naujoks, F., \& Totzke, I. (2014). Behavioral adaptation caused by predictive warning systems - The case of congestion tail warnings. Transportation Research Part F: Traffic Psychology and Behaviour, 26, 49-61. https://doi.org/10.1016/j.trf.2014.06.010

Office of Defects Investigations. (2017). ODI Resume Investigation PE 16-007 (PE No. 16-007).

Österreichische Automobil-, Motorrad- und Touringclub. (2014). Hochautomatisiertes Fahren [Highly automated driving]. Retrieved from http://tv.oeamtc.at/themen/auto/hochautomatisiertesfahren.html

Parasuraman, R., \& Riley, V. (1997). Humans and automation: Use, misuse, disuse, abuse. Human Factors: The Journal of the Human Factors and Ergonomics Society, 39(2), 230-253. https://doi.org/10.1518/001872097778543886

Payre, W., Cestac, J., \& Delhomme, P. (2014). Intention to use a fully automated car: Attitudes and a priori acceptability. Transportation Research Part F: Traffic Psychology and Behaviour, 27, 252263. https://doi.org/10.1016/j.trf.2014.04.009

Payre, W., Cestac, J., \& Delhomme, P. (2016). Fully automated driving: Impact of trust and practice on manual control recovery. Human Factors: The Journal of the Human Factors and Ergonomics Society, 58(2), 229-241. https://doi.org/10.1177/0018720815612319

Plummer, M. (2003). JAGS: A program for analysis of Bayesian graphical models using Gibbs sampling. In Kurt Hornik, Friedrich Leisch, \& Achim Zeileis (Eds.), Proceedings of the 3rd International Workshop on Distributed Statistical Computing (DSC 2003). Vienna, Austria.

Pop, V. L., Shrewsbury, A., \& Durso, F. T. (2015). Individual differences in the calibration of trust in automation. Human Factors: The Journal of the Human Factors and Ergonomics Society, 57(4), 545-556. https://doi.org/10.1177/0018720814564422

R Core Team. (2016). R: A language and environment for statistical computing. Vienna, Austria. Retrieved from https://www.R-project.org

Radlmayr, J., Gold, C., Lorenz, L., Farid, M., \& Bengler, K. (2014). How traffic situations and nondriving related tasks affect the take-over quality in highly automated driving. Proceedings of the Human Factors and Ergonomics Society Annual Meeting, 58(1), 2063-2067. https://doi.org/10.1177/1541931214581434

Roberts, J., Hodgson, R., \& Dolan, P. (2011). “It's driving her mad”: Gender differences in the effects of commuting on psychological health. Journal of Health Economics, 30(5), 1064-1076. https://doi.org/10.1016/j.jhealeco.2011.07.006

Robson, K., Plangger, K., Kietzmann, J. H., McCarthy, I., \& Pitt, L. (2015). Is it all a game? Understanding the principles of gamification. Business Horizons, 58(4), 411-420. https://doi.org/10.1016/j.bushor.2015.03.006

Rouder, J. N., Speckman, P. L., Sun, D., Morey, R. D., \& Iverson, G. (2009). Bayesian t tests for accepting and rejecting the null hypothesis. Psychonomic Bulletin \& Review, 16(2), 225-237. https://doi.org/10.3758/PBR.16.2.225 
SAE International (2016, September 30). Taxonomy and definitions for terms related to driving automation systems for on-road motor vehicle. (Standard, J3016_201609).

Sauer, J., Chavaillaz, A., \& Wastell, D. (2015). Experience of automation failures in training: effects on trust, automation bias, complacency, and performance. Ergonomics, 1-28.

https://doi.org/10.1080/00140139.2015.1094577

Schaefer, K. E., Chen, J. Y. C., Szalma, J. L., \& Hancock, P. A. (2016). A meta-analysis of factors influencing the development of trust in automation: Implications for understanding autonomy in future systems. Human Factors: The Journal of the Human Factors and Ergonomics Society. Advance online publication. https://doi.org/10.1177/0018720816634228

Schönbrodt, F. D., \& Wagenmakers, E.-J. (2017). Bayes factor design analysis: Planning for compelling evidence. Psychonomic Bulletin \& Review. Advance online publication.

https://doi.org/10.3758/s13423-017-1230-y

Schönbrodt, F. D., Wagenmakers, E.-J., Zehetleitner, M., \& Perugini, M. (2015). Sequential hypothesis testing with Bayes factors: Efficiently testing mean differences. Psychological Methods. Advance online publication. https://doi.org/10.1037/met0000061

Schoorman, F. D., Mayer, R. C., \& Davis, J. H. (2007). An integrative model of organizational trust: Past, present, and future. Academy of Management Review, 32(2), 344-354.

https://doi.org/10.5465/AMR.2007.24348410

Seppelt, B. D., \& Lee, J. D. (2007). Making adaptive cruise control (ACC) limits visible. International Journal of Human-Computer Studies, 65(3), 192-205. https://doi.org/10.1016/j.ijhcs.2006.10.001

Shinar, D., Tractinsky, N., \& Compton, R. (2005). Effects of practice, age, and task demands, on interference from a phone task while driving. Accident Analysis \& Prevention, 37(2), 315-326. https://doi.org/10.1016/j.aap.2004.09.007

Skitka, L. J., Mosier, K. L., Burdick, M., \& Rosenblatt, B. (2000). Automation bias and errors: Are crews better than individuals? The International Journal of Aviation Psychology, 10(1), 85-97. https://doi.org/10.1207/S15327108IJAP1001_5

Stanton, N. A., \& Young, M. S. (1998). Vehicle automation and driving performance. Ergonomics, 41(7), 1014-1028. https://doi.org/10.1080/001401398186568

The Guardian. (2016). Tesla driver dies in first fatal crash while using autopilot mode. Retrieved from https://www.theguardian.com/technology/2016/jun/30/tesla-autopilot-death-self-driving-car-elonmusk

de Waard, D., van der Hulst, M., Hoedemaeker, M., \& Brookhuis, K. (1999). Driver behavior in an emergency situation in the automated highway system. Transportation Human Factors, 1(1), 6782. https://doi.org/10.1207/sthf0101_7

Wagner, M., \& Koopman, P. (2015). A philosophy for developing trust in self-driving cars. In G. Meyer \& S. Beiker (Eds.), Lecture Notes in Mobility. Road Vehicle Automation 2 (pp. 163-171). Cham: Springer International Publishing.

Walker, G. H., Stanton, N. A., \& Salmon, P. (2016). Trust in vehicle technology. International Journal of Vehicle Design, 70(2), 157. https://doi.org/10.1504/IJVD.2016.074419

Wickens, C. D., \& Xu, X. (2002). Automation trust, reliability and attention (Technical Report No. AHFD-02-14/MAAD-02-2). Savoy, Illinois.

Wiegmann, D. A., McCarley, J. S., Kramer, A. F., \& Wickens, C. D. (2006). Age and automation interact to influence performance of a simulated luggage screening task. Aviation, space, and environmental medicine, 77(8), 825-831.

Wilcox, R. R. (2012). Modern statistics for the social and behavioral sciences: A practical introduction. Boca Raton, Fla.: CRC Press/Chapman \& Hall. 